\title{
Upscaling of saturated conductivity for Hortonian runoff modelling
}

\author{
Derek Karssenberg * \\ Department of Physical Geography, Faculty of Geosciences, Utrecht University, P.O. Box 80115, 3508 TC Utrecht, The Netherlands
}

Received 18 August 2004; received in revised form 20 April 2005; accepted 16 June 2005

Available online 3 January 2006

\begin{abstract}
Stochastic and deterministic upscaling techniques are developed that upscale saturated conductivity at the support of $0.04 \mathrm{~m}^{2}$ to representative actual infiltration $\left(I_{\mathrm{b}}\right)$ for support units (blocks) of $10^{1}-10^{4} \mathrm{~m}^{2}$, as a function of steady state rainfall and runon to the block, under Hortonian runoff (infiltration excess overland flow). Parameters in the upscaling techniques represent the surface runoff flow pattern and the spatial probability distribution of saturated conductivity within the $10^{1}-10^{4} \mathrm{~m}^{2}$ block. The stochastic upscaling technique represents the spatial process of infiltration and runoff using a simple process-imitating model, estimating $I_{\mathrm{b}}$ using Monte Carlo simulation. The deterministic upscaling technique aggregates these processes by a deterministic function relating rainfall and runon to $I_{\mathrm{b}}$. The stochastic upscaling technique is shown to be capable to upscale saturated conductivity derived from ring infiltrometers to $I_{\mathrm{b}}$ values of plots $\left(1 \mathrm{~m}^{2}\right)$ corresponding to measured $I_{\mathrm{b}}$ values using rainfall simulators. It is shown that both upscaling techniques can be used to estimate $I_{\mathrm{b}}$ for each time step and each block in transient rainfall-runoff models, giving better estimates of cumulative runoff from a hillslope and a small catchment than model runs that do not use upscaling techniques.
\end{abstract}

(c) 2005 Elsevier Ltd. All rights reserved.

Keywords: Upscaling; Infiltration; Hortonian runoff; Rainfall-runoff modelling; Rainfall simulation; Ring infiltrometer

\section{Introduction}

Infiltration can be considered as a one-dimensional process, also referred to as point-, local- or small-scale process [59], into the soil when it is described or measured at a small area (e.g., $\left.10^{-2} \mathrm{~m}^{2}\right)$. For larger areas, also referred to as the large scale [59] or block scale, infiltration has to be considered as a spatial process with an interaction between runoff and the infiltration processes in the soil because the availability of water for infiltration becomes dependent on rain and runon, whereby runon is determined by the same interaction process upstream. This issue of scale dependency of infiltration needs to be considered when applying a distributed model for predicting Hortonian runoff (infiltration excess runoff) in a catchment because there is a difference between the sup-

\footnotetext{
${ }^{*}$ Tel.: +31 30 2532768; fax: +31 302531145 .

E-mail address: d.karssenberg@geo.uu.nl
}

port [5] of field measurements of infiltration that are often used to estimate infiltration parameters and the support of the units used in the rainfall-runoff model for which the parameter values are needed. Field measurements of infiltration result in infiltration parameter values representative for a support of $0.002-0.05 \mathrm{~m}^{2}$ when ring infiltrometers are used, up to $0.5-10 \mathrm{~m}^{2}$ when plot experiments under artificial or natural rainfall are applied. Since the use of such small model units for modelling catchments would result in unacceptably long computation times, rainfall-runoff models use units with a larger support. These models discretise a catchment in grid cells or hillslopes (e.g., [56]), which have a typical size of $10^{1}-10^{4} \mathrm{~m}^{2}$, and a conceptualization and parameterization of infiltration is needed representative for the units at this larger support. These large-scale units are often referred to as 'blocks', which is done in the rest of this paper. Note that these blocks can have any shape here, e.g., grid cells or hillslopes. 


\begin{tabular}{|c|c|c|c|}
\hline \multicolumn{4}{|c|}{ Nomenclature } \\
\hline$a$ & fraction (-) of the block receiving inflow, in $g$ & $K_{p}^{*}$ & saturated conductivity $(\mathrm{mm} / \mathrm{h})$ measured \\
\hline$a_{\mathrm{g}}$ & parameter $(\mathrm{mm} / \mathrm{h})$ in Philip's equation & & \\
\hline $\begin{array}{l}a_{\text {var }} \\
B_{i}\end{array}$ & range in $\gamma(\mathbf{h})$ & $K_{\mathrm{st}}\left(\mathbf{s}_{i}\right)$ & $\begin{array}{l}\text { standardized saturated conductivity (-) of the } \\
\text { unit } u\left(\mathbf{s}_{)}\right)\end{array}$ \\
\hline & $u\left(\mathbf{s}_{i}\right)$ at the edge of the block $\left(\mathrm{m}^{2}\right)$ & $l(t)$ & average travel time (s) at $t$ of water from the \\
\hline$b$ & parameter in $\mathrm{h}$ & & edge of the hillslope to the outflow point \\
\hline$b_{p}$ & $\begin{array}{l}\text { parameter defining the shape of } g \text { in the } p_{\text {st }} \\
\text { direction }\end{array}$ & $m$ & $\begin{array}{l}\text { number of neighboring units with outflow to } \\
\text { a unit }\end{array}$ \\
\hline$b_{q}$ & parameter defining the shape of $g$ in the $q_{\mathrm{st}}$ & $m_{K_{p}(\mathbf{s})}$ & expectation of $K_{p}(\mathbf{s})$ \\
\hline$c$ & $\begin{array}{l}\text { direction } \\
\text { cumulative }\end{array}$ & $m_{\mathrm{mc}}$ & $\begin{array}{l}\text { number of loops in the Monte Carlo simula- } \\
\text { tion to solve } G\end{array}$ \\
\hline$D$ & two-dimensional domain & $m_{Z(\mathbf{s})}$ & expectation of $Z(\mathbf{s})$ \\
\hline$d$ & variable in $\mathrm{h}$ & $n_{\text {grid }}$ & number of units within a block \\
\hline & measured cumulative discharge $\left(\mathrm{m}^{3}\right)$ & $O_{\text {in, st }}\left(\mathbf{s}_{i}\right.$ & i) standardized total inflow (-) from neighbor- \\
\hline$d_{\mathrm{m}, \max }$ & $\begin{array}{l}\text { maximum value of measured cumulative dis- } \\
\text { charge }\left(\mathrm{m}^{3}\right)\end{array}$ & $O_{\text {out }, \mathrm{st}} \mathrm{s}$ & $\begin{array}{l}\text { ing units to a unit } u\left(\mathbf{s}_{i}\right) \\
\left.\mathbf{s}_{i}\right) \text { standardized outflow (-) of a unit } u\left(\mathbf{s}_{i}\right)\end{array}$ \\
\hline$d_{\mathrm{m}, \min }$ & $\begin{array}{l}\text { minimum value of measured cumulative dis- } \\
\text { charge }\left(\mathrm{m}^{3}\right)\end{array}$ & $O_{\text {out }, \mathrm{st}} \mathrm{s}$ & $\begin{array}{l}\left.\mathbf{s}_{i, n}\right) \text { standardized outflow (-) from a directly } \\
\text { neighboring unit } u\left(\mathbf{s}_{i, n}\right) \text { received by unit } u\left(\mathbf{s}_{i}\right)\end{array}$ \\
\hline$d_{\mathrm{s}}$ & simulated cumulative discharge $\left(\mathrm{m}^{3}\right)$ & $\Omega_{\mathrm{b}}$ & fraction $(-)$ of the block receiving inflow \\
\hline & total standardized runon $(-)$ to a unit & Pattern & $\imath_{p}$ overland flow pattern between units within \\
\hline$\phi_{i, j}^{*}$ & $\begin{array}{l}\text { measured decile }(\mathrm{mm} / \mathrm{h}) \\
\text { modelled decile }(\mathrm{mm} / \mathrm{h})\end{array}$ & $p_{\mathrm{b}}$ & net rain $(\mathrm{mm} / \mathrm{h})$ reaching the surface of a \\
\hline$\gamma(\mathbf{h})$ & semivariogram of $Z(\mathbf{s})$ & & s \\
\hline$G$ & stochastic upscaling technique & $p_{\text {st }}$ & standardized net rain $(-)$ reaching the surface \\
\hline$g$ & deterministic upscaling technique (function) & & of a block \\
\hline$\Gamma$ & $\begin{array}{l}\text { direction (degrees) of wheel tracks within } \\
\text { block }\end{array}$ & $q_{\mathrm{b}}$ & $\begin{array}{l}\text { inflow }(\mathrm{mm} / \mathrm{h}) \text { to a block from neighboring } \\
\text { blocks }\end{array}$ \\
\hline $\mathbf{h}$ & separation vector $(\mathrm{m})$ in $\gamma(\mathbf{h})$ & $q_{\mathrm{st}}$ & standardized inflow (-) to a block from \\
\hline$I_{\mathrm{b}}$ & actual infiltration $(\mathrm{mm} / \mathrm{h})$ of a block & & uring blocks \\
\hline$I_{\mathrm{b}, \mathrm{st}}$ & $\begin{array}{l}\text { standardized actual infiltration }(-) \text { of the } \\
\text { block }\end{array}$ & $r_{\mathrm{st}}\left(\mathbf{s}_{i}\right)$ & $\begin{array}{l}\text { standardized runon (-) to a unit } u\left(\mathbf{s}_{i}\right) \text { over the } \\
\text { edge of the block }\end{array}$ \\
\hline$i_{\mathrm{ch}}$ & representative actual infiltration $(\mathrm{mm} / \mathrm{h})$ in & $\mathbf{S}$ & spatial index \\
\hline & the compartment receiving inflow & $s$ & $\mathrm{r}(\mathrm{mm} / \mathrm{h})$ in Philip's equation \\
\hline$i_{\text {nch }}$ & representative actual infiltration $(\mathrm{mm} / \mathrm{h})$ & $\sigma_{Z(\mathbf{s})}^{2}$ & maximum value of the covariance in $\gamma(\mathbf{h})$ \\
\hline & in the compartment receiving net rain & $\mathrm{SS}$ & $\begin{array}{l}\text { sum of squares } \\
\text { time }(\mathrm{s})\end{array}$ \\
\hline$I_{\mathrm{st}}\left(\mathbf{s}_{i}\right)$ & $\begin{array}{l}\text { only } \\
\text { standardized actual infiltration (-) of a unit } \\
u\left(\mathbf{s}_{i}\right)\end{array}$ & $\begin{array}{l}t \\
t_{s}(t) \\
|u|\end{array}$ & $\begin{array}{l}\text { the maximum of all } t-l(t) \text { values in the past } \\
\text { area }\left(\mathrm{m}^{2}\right) \text { of units }\end{array}$ \\
\hline$I_{\mathrm{b}, p}^{*}$ & $\begin{array}{l}\text { actual infiltration }(\mathrm{mm} / \mathrm{h}) \text { measured with } \\
\text { rainfall simulation experiments }(\mathrm{mm} / \mathrm{h})\end{array}$ & $u\left(\mathbf{s}_{i}\right)$ & $\begin{array}{l}\text { unit at location } \mathbf{s}_{i} \text { on a rectangular grid within } \\
\text { a block }\end{array}$ \\
\hline$I_{\mathrm{b}, p}$ & $\begin{array}{l}\text { upscaled actual infiltration }(\mathrm{mm} / \mathrm{h}) \text { represen- } \\
\text { tative for rainfall simulation plots }\end{array}$ & $u\left(\mathbf{s}_{i, n}\right)$ & $\begin{array}{l}\text { unit } n \text { with outflow to a neighboring unit at } \\
\text { location } \mathbf{s}_{i}\end{array}$ \\
\hline$I_{\mathrm{b}, h}$ & $\begin{array}{l}\text { upscaled actual infiltration }(\mathrm{mm} / \mathrm{h}) \text { represen- } \\
\text { tative for catchment B }\end{array}$ & & $\begin{array}{l}\text { area }\left(\mathrm{m}^{2}\right) \text { of the block } \\
\text { variable in } h\end{array}$ \\
\hline & decile number in $(25)$ & $Z(\mathbf{s})$ & a multivariable normal and stationary ran- \\
\hline$K_{p}(\mathbf{s})$ & $\begin{array}{l}\text { spatial probability distribution of saturated } \\
\text { conductivity }(\mathrm{mm} / \mathrm{h}) \text { in a block. Values repre- }\end{array}$ & & \\
\hline$K_{p}\left(\mathbf{s}_{i}\right)$ & $\begin{array}{l}\text { sentative at the support of a unit } \\
\text { saturated conductivity }(\mathrm{mm} / \mathrm{h}) \text { of the unit } \\
u\left(\mathbf{s}_{i}\right)\end{array}$ & $\begin{array}{l}\text { Note: } \mathrm{U} \\
\text { fields } \mathrm{W} \\
\text { variable }\end{array}$ & $\begin{array}{l}\text { Uppercase letters denote stochastic variables or } \\
\text { while lowercase letters denote realizations. A } \\
\text { e given here as a stochastic variable (in upper- }\end{array}$ \\
\hline$K_{i}(\mathbf{s})$ & $\begin{array}{l}\text { spatial probability distribution of saturated } \\
\text { conductivity }(\mathrm{mm} / \mathrm{h}) \text { in a block }\end{array}$ & $\begin{array}{l}\text { case) } \\
\text { reali }\end{array}$ & $\begin{array}{l}\text { in be used in the text in lowercase to represent a } \\
\text { ion of the same variable. }\end{array}$ \\
\hline
\end{tabular}


From the above, it is clear that representative infiltration parameters and a correct conceptualization of the infiltration process for blocks can only be derived from field measurements of infiltration using an upscaling technique [5] that takes into account the spatial processes of runoff and infiltration within the blocks. Although many authors have stressed the need for upscaling techniques for infiltration $[3,5,6,8,9,23]$, research in this field is still in its infancy compared to similar research in the field of ground water flow modelling. Existing methods for deriving representative parameters for infiltration (e.g., $[25,47])$ mostly ignore the interaction between surface runoff and infiltration or do not deal with spatially variable runoff (e.g., [13,17,21,24,33,59,62]), although this interaction is known to be important $[6,18,39,40,54,61]$. Merz et al. [38], comparing different approaches for modelling plot scale infiltration, find best results when spatial variation of runoff within the plot is taken into account.

One of the main reasons why, so far, few successful upscaling techniques have been described is the problem encountered with the representative parameter concept when applied to natural rainstorms. This is due to the transient character of natural rainfall, runoff and infiltration [7,53,59]. Smith and Diekkrüger [53] showed that a representative saturated conductivity parameter, valid during the whole duration of rainstorms with variable characteristics, could not be found. For this reason, an approach is introduced here taking into account transient conditions. Following an approach that fits into the disaggregation-aggregation framework described in [59], an upscaling technique $(G)$ is developed calculating the block-scale actual infiltration $I_{\mathrm{b}}(t)(\mathrm{mm} / \mathrm{h}$ at time $t)$ representative for a block with a support of $10^{1}-10^{4} \mathrm{~m}^{2}$ :

$I_{\mathrm{b}}(t)=G\left(p_{\mathrm{b}}(t), q_{\mathrm{b}}(t), K_{p}(\mathbf{s})\right.$, Pattern $\left._{p}\right)$

with the following properties of the block: $p_{\mathrm{b}}(t)$, the spatial average of the net rain $(\mathrm{mm} / \mathrm{h})$ reaching the surface; $q_{\mathrm{b}}(t)$, the total inflow $(\mathrm{mm} / \mathrm{h})$ from neighbouring blocks; $K_{p}(\mathbf{s})$, the spatial probability distribution of the pointscale saturated conductivity $(\mathrm{mm} / \mathrm{h})$ within the block, with s, a spatial index; and Pattern $_{p}$, the point-scale overland flow pattern within the block. Note that in this paper, symbols in uppercase denote stochastic variables or fields while the same symbols in lowercase refer to realizations of these stochastic variables or fields, see also the nomenclature. So, net rain and total inflow are considered as known, deterministic values, while the saturated conductivity and the flow pattern are considered as stochastic entities whose spatial probability distributions need to be derived by measurements at the point scale, for instance using ring infiltrometers to derive saturated conductivity, or by disaggregation [59] of large-scale values. Both approaches will be described in this paper.

The aims of this paper are (1) to propose upscaling techniques such as $G$ for saturated conductivity of the topsoil that upscale representative values of saturated conductivity with a support of $0.04 \mathrm{~m}^{2}$ (i.e., point-scale values) to $I_{\mathrm{b}}$ values representative for a support of up to $7500 \mathrm{~m}^{2}$ (i.e., block-scale values), and (2) to evaluate (i.e., test) [41] the techniques using field data.

In the first part of the paper a stochastic upscaling technique $G$ is described that upscales point-scale saturated conductivity under a steady state condition of rain, runoff and infiltration. Derived from the principles of $G$, which is stochastic, a deterministic upscaling technique $g$, a function, is described. In the second part of the paper, the upscaling techniques are evaluated using field data. First, it is evaluated whether the upscaling technique $G$ can explain the measured scale transform of infiltration from the point scale of ring infiltrometers to the plot scale used in rainfall simulations. Second, the upscaling techniques $G$ and $g$ are applied to derive representative values of Hortonian infiltration as input to a distributed rainfall-runoff model. This approach is evaluated by comparing measured discharge generated by Hortonian runoff on a hillslope and a small catchment to discharge predicted with the rainfall-runoff model using the upscaled infiltration.

\section{Upscaling techniques}

\subsection{Saturated conductivity and flow pattern within a block}

The saturated conductivity is represented by the random field $\left\{K_{i}(\mathbf{s}): \mathbf{s} \in D\right\}(\mathrm{mm} / \mathrm{h})$ where $\mathbf{s}$ is a spatial index in the two-dimensional domain $D$ corresponding to the domain of the block. In the block, flow over the surface and infiltration are assumed to occur over square units $u(\mathbf{s})$, with an area $|u|\left(\mathrm{m}^{2}\right)$, referred to as the point scale. Since $|u|$ is chosen to be very small, typically $0.04 \mathrm{~m}^{2}$, it is assumed that net rain on a unit and lateral inflow to the unit are distributed evenly over the unit. Under this assumption, the saturated conductivity $K_{p}(\mathbf{s})$ at the support of a unit is:

$K_{p}(\mathbf{s})=\frac{\int_{u} K_{i}(\mathbf{s}) \mathrm{d} \mathbf{s}}{|u|}$.

At the support $|u|$, the plausible assumption can be made that $K_{p}(\mathbf{s})$ has a lognormal distribution $[12,35,46,48,49]$ :

$K_{p}(\mathbf{s})=\mathrm{e}^{Z(\mathbf{s})}$.

Furthermore, it is assumed that $Z(\mathbf{s})$ is a multivariable normal and stationary random spatial function. Thus, $\{Z(\mathbf{s}): \mathbf{s} \in D\}$ is defined by:

$m_{Z(\mathbf{s})}=E\{Z(\mathbf{s})\}$

$\gamma(\mathbf{h})=\frac{1}{2} E\left\{(Z(\mathbf{s})-Z(\mathbf{s}+\mathbf{h}))^{2}\right\}$, 
where $E$ represents expectation. The quantity $\gamma(\mathbf{h})$, which is a function of the separation vector $\mathbf{h}(\mathrm{m})$, is called the semivariogram defining the spatial structure of $Z(\mathbf{s})$. Due to the absence of other information, a spherical model is assumed for the semivariogram:

$$
\gamma(\mathbf{h})= \begin{cases}\sigma_{Z(\mathbf{s})}^{2}\left(\frac{3}{2} \frac{|\mathbf{h}|}{a_{\mathrm{var}}}-\frac{1}{2} \frac{|\mathbf{h}|^{3}}{a_{\mathrm{var}}^{3}}\right) & \text { for } 0 \leqslant|\mathbf{h}| \leqslant a_{\mathrm{var}}, \\ \sigma_{Z(\mathbf{s})}^{2} & \text { for }|\mathbf{h}|>a_{\mathrm{var}}\end{cases}
$$

with $a_{\mathrm{var}}(\mathrm{m})$, range of the semivariogram defining the spatial scale of variation; $\sigma_{Z(\mathbf{s})}^{2}$, maximum value of the covariance. The expectation (mean) of $K_{p}(\mathbf{s})$ is [1]:

$m_{K_{p}(\mathbf{s})}=E\left\{K_{p}(s)\right\}=\mathrm{e}^{\left.m_{Z(\mathbf{s})}\right) \frac{1}{2} \sigma_{Z(\mathbf{s})}^{2}}$.

Increasing $\sigma_{Z(\mathbf{s})}^{2}$ results in a probability distribution of $K_{p}(\mathbf{s})$ with a higher variance and skewness. Since the stochastic upscaling technique described in the next section can only be solved by Monte Carlo simulation, the distribution of $K_{p}(\mathbf{s})$ is represented by a set of realizations which are generated by sequential Gaussian simulation with Latin hypercube sampling [43].
Surface flow within the block is represented by flow over a rectangular grid of units $u\left(\mathbf{s}_{i}\right)$, with $\mathbf{s}_{i}, i=$ $1, \ldots, n_{\text {grid }}$, the locations of the centre of the units at the grid, with a grid spacing corresponding to the length and width of the units $(\sqrt{|u|}, \mathrm{m}$, Fig. 1B). The upscaling technique assumes that the exact surface flow pattern $\left(\right.$ Pattern $_{p}$ in (1)) between units is unknown, although general characteristics, such as the large-scale change in topography and the type of microrelief, are known. For each realization, the flow pattern is generated in two steps. In the first step, a realization of the elevation model at a resolution of the units is drawn. This is done for three different scenarios:

1. Sheet flow. The realization of the elevation model consists of the deterministic elevation model, which represents the large-scale change in topography which is assumed to be known, plus a random component which is a realization of a random field with a spherical semivariogram with range $=1000 \mathrm{~m}$ and variance $=5 \times 10^{-5} \mathrm{~m}^{2}$.

2. Flow with microscale variation. Idem, but with range $=0.5 \mathrm{~m}$ and variance $=0.02 \mathrm{~m}^{2}$.

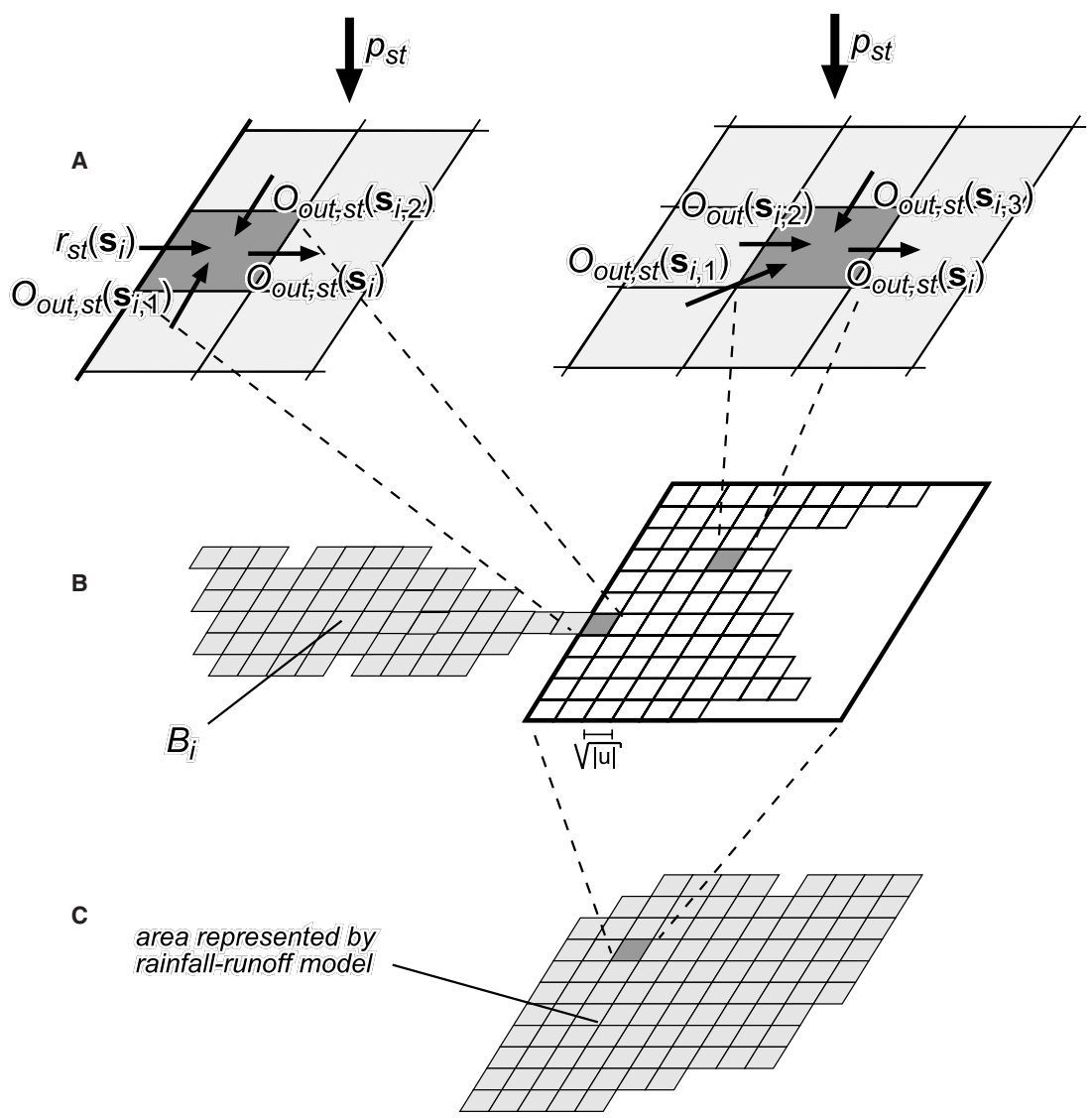

Fig. 1. Discretisation and flow patterns used in the stochastic upscaling technique. (B) Block discretised in units with area $|u|\left(\mathrm{m}^{2}\right)$, supplying catchment area $B_{i}$ shown of one unit at the edge of the block; (A) input and output fluxes for one unit; left, unit at the edge of the block; right: unit not at the edge of the block. Although the block can have any shape, it is shown here as a square area corresponding to a model unit of a distributed rainfall-runoff model, as shown in (C). 
3. Flow with wheel tracks. The random component is a realization of relief caused by wheel tracks. This wheel track relief consists of parallel, straight wheel tracks in a direction $\Gamma$ (degrees), with a constant interval between the wheel track centres of $1.25 \mathrm{~m}$, a wheel track width of $0.5 \mathrm{~m}$, and a depth of $0.01 \mathrm{~m}$. The direction $\Gamma$ is a random variable with an average direction and a variance of 1 . For each realization, the random component was obtained by generating the wheel track pattern using the above given constants and a realization of $\Gamma$.

The second step in the derivation of the flow pattern between units involves the calculation of the direction of flow for each unit $u\left(\mathbf{s}_{i}\right)$ from these realizations of the elevation model. This is done by assigning to each unit a flow direction to one of the eight steepest downstream neighbouring units (8-point pour algorithm, [10]). Fig. 2 gives example realizations of the resulting flow patterns.

\subsection{Stochastic upscaling technique $G$}

The stochastic upscaling technique uses the overland flow pattern between the units to represent infiltration under Hortonian runoff. Any unit draining to a particular unit $u\left(\mathbf{s}_{i}\right)$ is called a neighbouring upstream unit $u\left(\mathbf{s}_{i, n}\right), n=1, \ldots, m$ (Fig. 1A), with $m$ the number of neighbouring units draining to the unit. Under the assumptions of (1) an even distribution of net rainfall and runon over each unit, and (2) a steady state situation resulting in an infiltration capacity of a unit that equals the saturated conductivity of the unit, the actual infiltration of a unit can be calculated as:

$$
\begin{aligned}
& I_{\mathrm{st}}\left(\mathbf{s}_{i}\right)=\min \left(p_{\mathrm{st}}+O_{\mathrm{in}, \mathrm{st}}\left(\mathbf{s}_{i}\right)+r_{\mathrm{st}}\left(\mathbf{s}_{i}\right), K_{\mathrm{st}}\left(\mathbf{s}_{i}\right)\right) \quad \text { with } \\
& p_{\mathrm{st}}=\frac{p_{\mathrm{b}}}{m_{K_{\mathrm{b}}(\mathbf{s})}}, \quad K_{\mathrm{st}}\left(\mathbf{s}_{i}\right)=\frac{K_{p}\left(\mathbf{s}_{i}\right)}{m_{K_{p}(\mathbf{s})}}, \\
& O_{\mathrm{in}, \mathrm{st}}\left(\mathbf{s}_{i}\right)=\sum_{n=1, \ldots, m} O_{\text {out }, \mathrm{st}}\left(\mathbf{s}_{i, n}\right),
\end{aligned}
$$
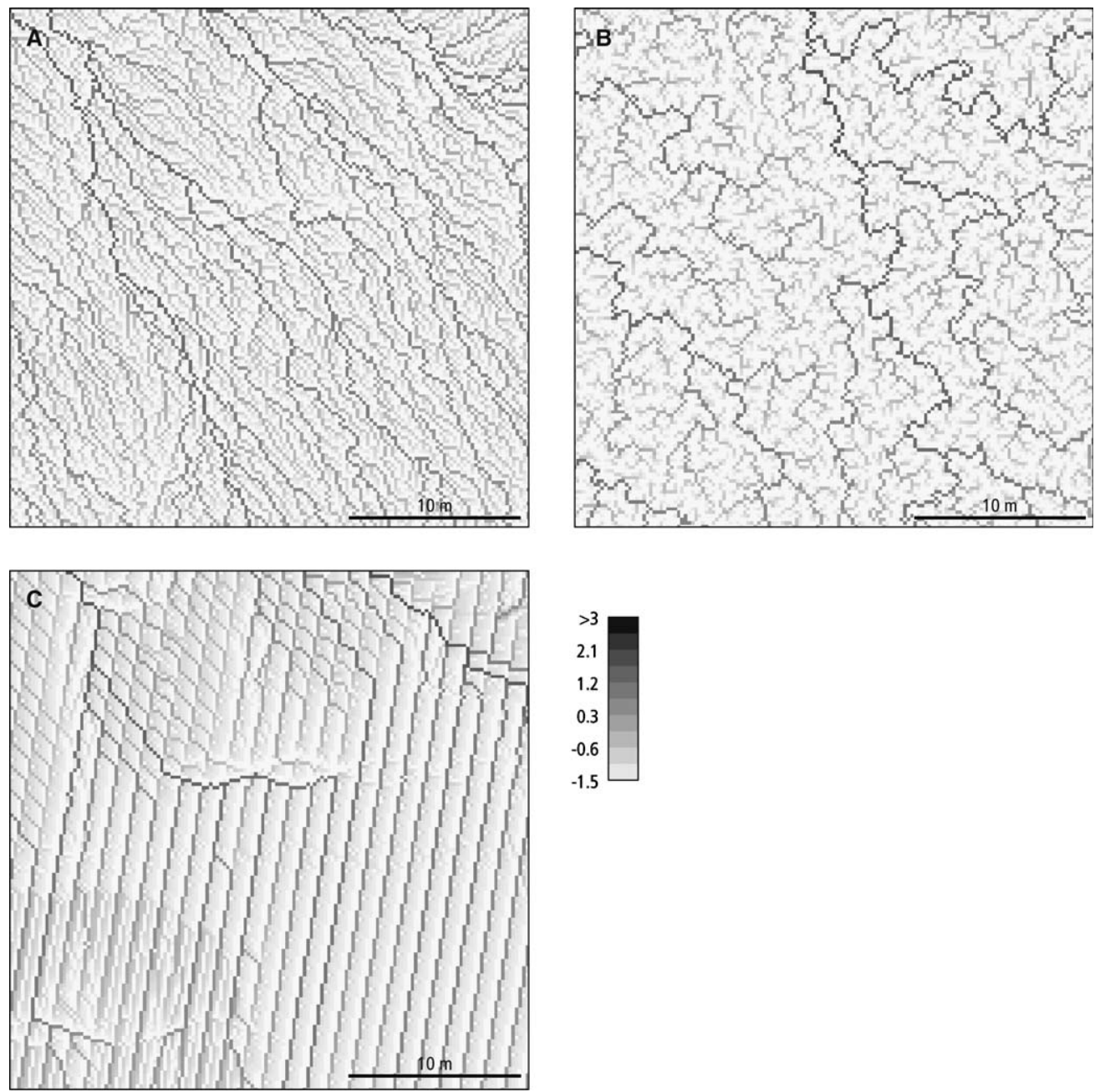

Fig. 2. Flow patterns $\left(\right.$ Pattern $\left._{p}\right)$. Grey scales represent the $\log _{10}$ of the catchment area $\left(\mathrm{m}^{2}\right)$ of each unit. (A) Sheet flow, (B) flow with microscale variation of topography, (C) flow with wheel tracks. 
$O_{\text {out }, \mathrm{st}}\left(\mathbf{s}_{i}\right)=O_{\mathrm{in}, \mathrm{st}}\left(\mathbf{s}_{i}\right)+p_{\mathrm{st}}+r_{\mathrm{st}}\left(\mathbf{s}_{i}\right)-I_{\mathrm{st}}\left(\mathbf{s}_{i}\right)$,

where ' $\min (x, y)$ ' assigns the minimum value of $x$ and $y$. The subscripts 'st' denote values (-) standardized to values valid for a unit mean saturated conductivity. These are (Fig. 1A): $p_{\text {st }}$, rainfall; $I_{\mathrm{st}}\left(\mathbf{s}_{i}\right)$, actual infiltration of the unit; $O_{\text {out,st }}\left(\mathbf{s}_{i}\right)$, outflow to a directly neighbouring unit; $O_{\text {out,st }}\left(\mathbf{s}_{i, n}\right)$, outflow from a neighboring unit $u\left(\mathbf{s}_{i, n}\right)$ received by the unit; $O_{\text {in,st }}\left(\mathbf{s}_{i}\right)$, total inflow from neighboring units $n=1, \ldots, m$ to the unit; $K_{\mathrm{st}}\left(\mathbf{s}_{i}\right)$, saturated conductivity of the unit; $r_{\mathrm{st}}\left(\mathbf{s}_{i}\right)$, runon over the edge of the block, which is zero for units not at the edge of the block. The amount of runon summed over all units at the edge of the block equals the total inflow $\left(q_{\mathrm{b}}\right.$ in (1)) from directly neighboring blocks. It is assumed that each unit at the edge of the block receives an amount of this inflow proportional to its supplying catchment area outside the unit (Fig. 1B):

$r_{\mathrm{st}}\left(\mathbf{s}_{i}\right)=\frac{B_{i}}{\sum_{i \in \mathrm{edge}} B_{i}} \cdot \frac{|u|}{\left|u_{d}\right|} q_{\mathrm{st}} \quad$ with $q_{\mathrm{st}}=\frac{q_{\mathrm{b}}}{m_{K_{p(\mathrm{~s})}}}$,

where $\left|u_{d}\right|$, area of the block; $q_{\mathrm{st}}(-)$, standardized inflow from neighboring blocks; $B_{i}$, catchment area $\left(\mathrm{m}^{2}\right)$ outside the block of a unit $u\left(\mathbf{s}_{i}\right)$ lying at the edge of the block; $\sum_{i \in \text { edge }} B_{i}$, the total catchment area outside the block $\left(\mathrm{m}^{2}\right)$ of all units lying at the edge of the block. The catchment areas $B_{i}$ and $\sum_{i \in \text { edge }} B_{i}$ are calculated using the flow pattern between units in neighboring blocks. This flow pattern is derived following the procedure also applied for the block itself (see Section 2.1).

The standardized representative actual infiltration $\left(I_{\mathrm{b}, \mathrm{st}},-\right)$ of the block is:

$I_{\mathrm{b}, \mathrm{st}}=\frac{\sum_{i=1, \ldots, n_{\text {grid }}} I_{\mathrm{st}}\left(\mathbf{s}_{i}\right)}{n_{\text {grid }}}$.

And it is clear that the representative actual infiltration $(\mathrm{mm} / \mathrm{h})$ of the block is:

$I_{\mathrm{b}}=I_{\mathrm{b}, \mathrm{st}} m_{K_{p}(\mathbf{s})}$.

Also, the upscaling technique calculates $\Omega_{\mathrm{b}}(-)$, which is the area that is both (1) inside the block, and (2) downstream of one or more units at the edge of the block receiving water from neighboring blocks, divided by $\left|u_{d}\right|$. This area is calculated using the flow pattern between units.

To summarize, the upscaling technique $G$ derives $I_{\mathrm{b}}$ and $\Omega_{\mathrm{b}}$ of a block with Eqs. (2)-(13) as a function of (1) the spatial probability distribution of $K_{p}(\mathbf{s})$ and the flow pattern Pattern $n_{p}$ in the block, and (2) the net rain $p_{\mathrm{b}}$ and the inflow from neighboring blocks $q_{\mathrm{b}}$. The Monte Carlo simulation approach solves $G$ in two steps $[22,26]$. Step 1. Repeat $m_{\mathrm{mc}}$ times: (a) generate a realization of $K_{p}(\mathbf{s})$ and Pattern $_{p}$, (b) with these two realiza- tions, evaluate (8)-(13) with a given amount of rainfall $p_{\mathrm{b}}$ and inflow $q_{\mathrm{b}}$, and store the model outcome (realization) of $I_{\mathrm{b}}$ and $\Omega_{\mathrm{b}}$. Step 2. The $m_{\mathrm{mc}}$ model realizations represent $I_{\mathrm{b}}$ and $\Omega_{\mathrm{b}}$, and are used to calculate parameters describing the distribution of these variables. $G$ is run for different combinations of $p_{\mathrm{b}}$ and $q_{\mathrm{b}}$ values to derive the effect of these variables on $I_{\mathrm{b}}$ and $\Omega_{\mathrm{b}}$.

\subsection{Sensitivity analysis with the stochastic upscaling technique $G$}

The stochastistic upscaling technique $G$ is applied to a block consisting of a linear catchment of $1 \times 50$ units in a row. Fig. 3A shows one realization of $K_{p}(\mathbf{s})$ to illustrate the effect of increased rain intensity on infiltration, while keeping runon zero $\left(q_{\mathrm{st}}=0\right)$. Fig. 3B shows the resulting realization of the representative actual infiltration of the block. At lower rainfall intensities not all units infiltrate at the rate of the saturated conductivity since the input to these units, specifically rainfall plus inflow from upstream units, is less than the saturated conductivity. At these lower rainfall intensities, the representative actual infiltration of the block is lower than the mean saturated conductivity of the block. With increasing rain intensity, the actual infiltration increases since more water is available for infiltration. This increase stops at rain intensity $p_{\text {at_sat }}$ (Fig. 3B) where all units infiltrate at the saturated conductivity. Above this rain intensity, the actual infiltration corresponds to the mean of the saturated conductivity of the block.

To study the outcome of the stochastic upscaling technique under steady state conditions, relevant for rainfall-runoff plot studies, the technique is applied to a rectangular block with a slope of $0.01 \mathrm{~m} / \mathrm{m}$ in the longest direction of the block. To mimic plot studies, outflow from the block is restricted to the lower side, while the left and right side are closed. Inflow occurs at the upper side of the block only, while $B_{i}$ is set to the same positive value for all units at the upper side, meaning that (11) is not used here. The latter is done to represent homogenous input of water on the topside of the plot. All scenarios for different properties and sizes of the plot given in Table 1 are run with $m_{\mathrm{mc}}=800$, leading to stable estimates of the stochastic outcomes, and $\sqrt{|u|}=0.2 \mathrm{~m}$. Fig. 4 gives example realizations of the point-scale saturated conductivity $K_{p}(\mathbf{s})$ for the scenarios shown as a transect over 50 units, while Fig. 5 gives the outcomes of $G$. Without runon $\left(q_{\mathrm{st}}=0\right)$, the block actual infiltration $\left(I_{\mathrm{b}, \mathrm{st}}\right)$ increases with increasing rain intensity. At high rain intensities, the expectation of $I_{\mathrm{b}, \mathrm{st}}$ approaches 1. A similar increase in representative actual infiltration up to a maximum of $E\left\{K_{p}(\mathbf{s})\right\}$ was also found in the model of [6] and in measured and modelled saturated conductivity in [62,38]. Fields studies by $[11,15,19,23,28]$ also suggest an increase in representative actual infiltration with rain 
A
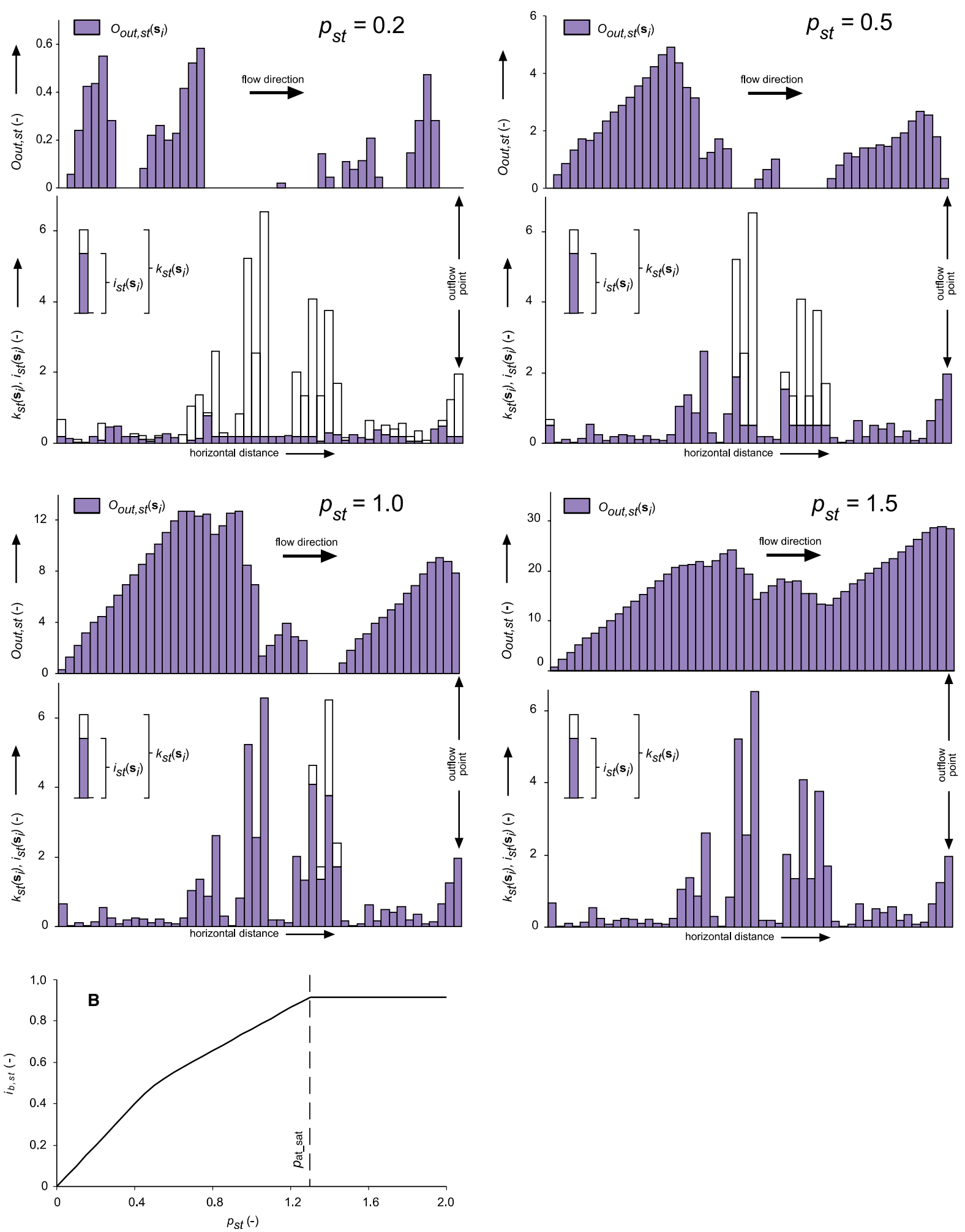

Fig. 3. Model input and output for one realization of $K_{\mathrm{st}}\left(\mathbf{s}_{i}\right)(-)$ for a linear block of $1 \times 50$ units with flow from left to right. (A) Standardized fluxes (-) per unit from uphill to downhill at different rain intensities $p_{\mathrm{st}} ; k_{\mathrm{st}}\left(\mathbf{s}_{i}\right)$, saturated conductivity; $i_{\mathrm{st}}\left(\mathbf{s}_{i}\right)$, actual infiltration; $O_{\text {out,st }}\left(\mathbf{s}_{i}\right)$, outflow. (B) Standardized representative actual infiltration $\left(i_{\mathrm{b}, \mathrm{st}},-\right)$ at different standardized rain intensities $\left(p_{\mathrm{st}},-\right)$ for the block.

intensity. Without rain $\left(p_{\mathrm{st}}=0\right)$, on the other hand, $I_{\mathrm{b}, \mathrm{st}}$ increases with increasing $q_{\mathrm{st}}$, approaching a value of $\Omega_{\mathrm{b}}$ when $q_{\text {st }}$ gets very high, which will be proven in Appen$\operatorname{dix} \mathrm{A}$ (see the following sections). For the scenarios with 
Table 1

Properties and size of the block to which the stochastic upscaling technique is applied to mimic rainfall-runoff plots

\begin{tabular}{lllll}
\hline Scenario & $a_{\mathrm{var}}(\mathrm{m})$ & $\sigma_{Z(\mathrm{~s})}^{2}$ & Size $(\mathrm{m}$, width $\times$ length $)$ & Flow pattern, i.e. Pattern \\
\hline Base & 0.6 & 2.0 & $2 \times 10$ & Sheet flow \\
Less skewed & 0.6 & 0.5 & $2 \times 10$ & Sheet flow \\
Larger range & 3.0 & 2.0 & $2 \times 10$ & Sheet flow \\
Larger block & 0.6 & 2.0 & $2 \times 40$ & Sheet flow \\
Microscale variation & 0.6 & 2.0 & $2 \times 10$ & Microscale variation \\
\hline
\end{tabular}

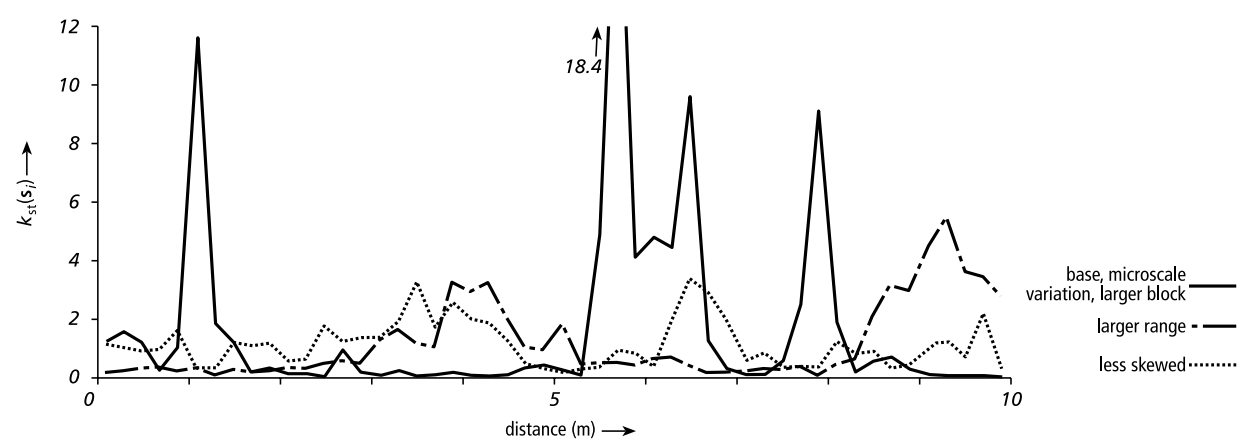

Fig. 4. Example realizations of $K_{\mathrm{st}}\left(\mathbf{s}_{i}\right)$ for the scenarios in Table 1, shown as transects of $10 \mathrm{~m}$.
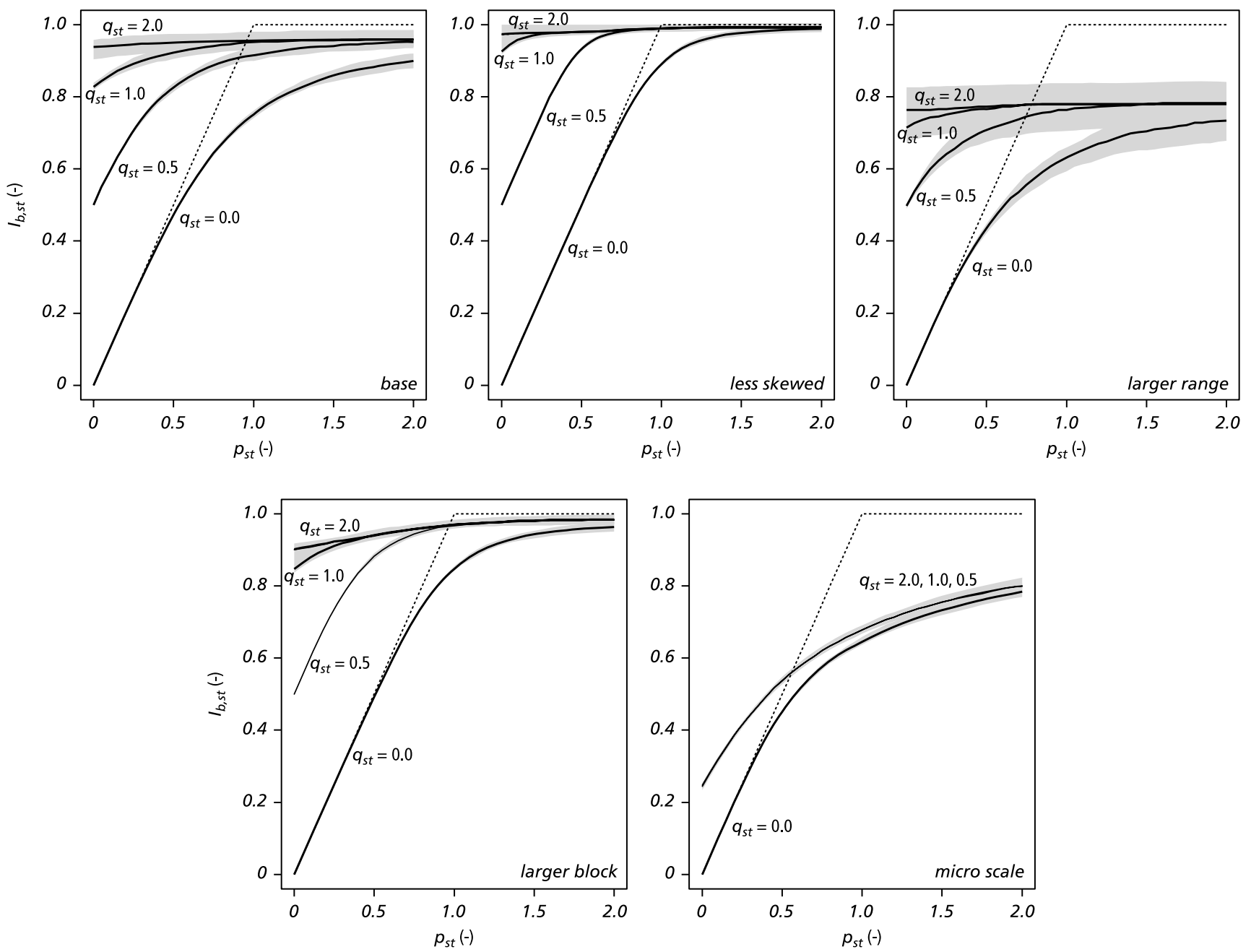

Fig. 5. Standardized representative actual infiltration $\left(I_{\mathrm{b}, \mathrm{st}},-\right)$ of a block against standardized rain intensity $\left(p_{\mathrm{st}},-\right)$ for standardized runon of $q_{\mathrm{st}}=0$, $0.5,1.0,1.5,2.0$. Each figure represents a scenario (Table 1). Solid lines, median; grey area, values between 45 th and 55th percentile. Dashed line is the effective saturated conductivity without spatial variation in $K_{p}(\mathbf{s})$ within the block for $q_{\mathrm{st}}=0$. 
sheet flow, almost all units are connected in upstream direction to the upper side of the block. As a result, $\Omega_{\mathrm{b}}$ is close to 1 , and high values of $q_{\mathrm{st}}$ result in values of $I_{\mathrm{b}, \mathrm{st}}$ close to 1 . For the microscale scenario having a flow pattern with many small branches, $\Omega_{\mathrm{b}}$ is lower, resulting in $I_{\mathrm{b}, \mathrm{st}}$ values much less than 1 at high $q_{\mathrm{st}}$ values (at $p_{\mathrm{st}}=0$ ). When both $p_{\mathrm{st}}$ and $q_{\mathrm{st}}$ are greater than zero, a combination of the described patterns occurs.

Comparing the base scenario with the other scenarios shows that the following properties of the block have an obvious effect on $I_{\mathrm{b}, \mathrm{st}}$, other simulations (not shown) with different changes in inputs give comparable results:

1. Spatial distribution of saturated conductivity $K_{p}(\mathbf{s})$. An increase in the value of the range parameter $\left(a_{\mathrm{var}}\right)$ of the saturated conductivity results in a decrease in the expectation of $I_{\mathrm{b}, \mathrm{st}}$ as shown by the larger range scenario. In addition, the difference between the 45th and 55th percentiles increases. A comparable decrease in actual infiltration was also found by the modelling study of [18] and to the author's best knowledge not corroborated by field studies.

2. Size of the block. Increasing the size of the block results in an increase in the expectation of $I_{\mathrm{b}, \mathrm{st}}$ as shown by the larger block scenario. The same trend was suggested by the modelling study of [8] and found in field studies [23,28,57], while the decreasing runoff with increasing slope length in [30] indicates the same. On the contrary, [15] does not find a difference in infiltration between plots of $1 \mathrm{~m}^{2}$ and $10 \mathrm{~m}^{2}$.

3. Runoff pattern. The microscale variation scenario represents a runoff pattern with more surface roughness compared to the base scenario, resulting in a runoff network with more convergent flow than the base scenario. This results in a lower $I_{\mathrm{b}, \mathrm{st}}$ compared with the base scenario.

\subsection{Deterministic upscaling technique $g$}

The stochastic upscaling technique $G$ has two disadvantages when applied to calculate block infiltration in rainfall-runoff models. First, the stochastic upscaling technique needs a large number of parameters describing the point-scale spatial probability distributions of the flow pattern $\left(\right.$ Pattern $\left._{p}\right)$ and the saturated conductivity $\left(K_{p}(\mathbf{s})\right)$. It will be almost impossible in a rainfall-runoff modelling study to identify each of these parameters for each model unit. Second, it is not feasible considering the large computation time of the stochastic upscaling technique to run it for each rainfall-runoff model unit and each time step. For this reason, a technique is developed here that aggregates the processes incorporated in the stochastic upscaling technique, leading to a deterministic upscaling technique with less parameters and negligible runtimes.
The form of the deterministic upscaling technique, referred to as $g$, is derived from concepts and outcomes of the stochastic model $G$. A fraction $a(-)$ of the total area of the block receives inflow from upstream units, which is represented by $E\left(\Omega_{\mathrm{b}}\right)$ in $G$. The representative actual infiltration of the block can be written as the weighted sum of the representative actual infiltration $\left(i_{\mathrm{ch}}, \mathrm{mm} / \mathrm{h}\right)$ in the compartment receiving inflow, having an area $a$, and the representative actual infiltration $\left(i_{\text {nch }}\right.$, $\mathrm{mm} / \mathrm{h}$ ) in the compartment receiving net rain only, with an area $1-a$ :

$i_{\mathrm{b}}=a \cdot i_{\mathrm{ch}}+(1-a) \cdot i_{\mathrm{nch}}$.

In most cases, the assumption can be made that the spatial probability distribution of the saturated conductivity in the two compartments is the same, as is done in the stochastic model $G$. If we make for the time being in addition the invalid assumptions of (1) an even distribution of all inflow and net rain within each compartment, and (2) absence of spatial variation in saturated conductivity within the two compartments, $i_{\mathrm{b}}$ can be written as:

$i_{\mathrm{b}}=a \cdot \min \left(p_{\mathrm{b}}+\frac{q_{\mathrm{b}}}{a}, m_{K_{p}(\mathrm{~s})}\right)+(1-a) \cdot \min \left(p_{\mathrm{b}}, m_{K_{p}(\mathrm{~s})}\right)$.

After some manipulation, (15) can be rewritten as:

$i_{\mathrm{b}}=\left\{\min \left[p_{\mathrm{st}}, 1\right]+\min \left[q_{\mathrm{st}}, a\left(1-\min \left[p_{\mathrm{st}}, 1\right]\right)\right]\right\} \cdot m_{K_{p}(\mathbf{s})}$.

Note that (16) is only true with the two invalid assumptions made for (15). Fig. 6 illustrates the shape of (16), using $i_{\mathrm{b}, \mathrm{st}}=i_{\mathrm{b}} / m_{K_{p}(\mathbf{s})}$. With spatial variation of inflow and saturated conductivity, $i_{\mathrm{b}}$ is lower than represented in (16), and the 'min' function is replaced by the function $h$ :

$$
\begin{aligned}
& i_{\mathrm{b}}=g\left(p_{\mathrm{st}}, q_{\mathrm{st}}\right) \cdot m_{K_{p}(\mathrm{~s})} \quad \text { with } \\
& \quad g\left(p_{\mathrm{st}}, q_{\mathrm{st}}\right)=h\left[p_{\mathrm{st}}, 1, b_{p}\right]+h\left[q_{\mathrm{st}}, a\left(1-h\left[p_{\mathrm{st}}, 1, b_{p}\right]\right), b_{q}\right]
\end{aligned}
$$

with $b_{p}, b_{q}$, parameters defining the shape of the function in the $p_{\mathrm{st}}$ and $q_{\mathrm{st}}$ direction, respectively.

The form of $h$ needs to follow the properties of the stochastic upscaling technique $G$ defined by (2)-(13). Some main properties of $h$ can be derived from $G$ as follows. Let $\Delta$ be a random variable representing the total standardized runon (-) to a unit:

$\Delta=p_{\mathrm{st}}+O_{\mathrm{in}, \mathrm{st}}\left(\mathbf{s}_{i}\right)+r_{\mathrm{st}}\left(\mathbf{s}_{i}\right)$.

Appendix A, Lemma 1 shows that the following limit is true:

$\lim _{\delta \rightarrow 0} E\left(\frac{I_{\mathrm{st}}(\Delta)}{\Delta} \mid \Delta \leqslant \delta\right)=1$ 


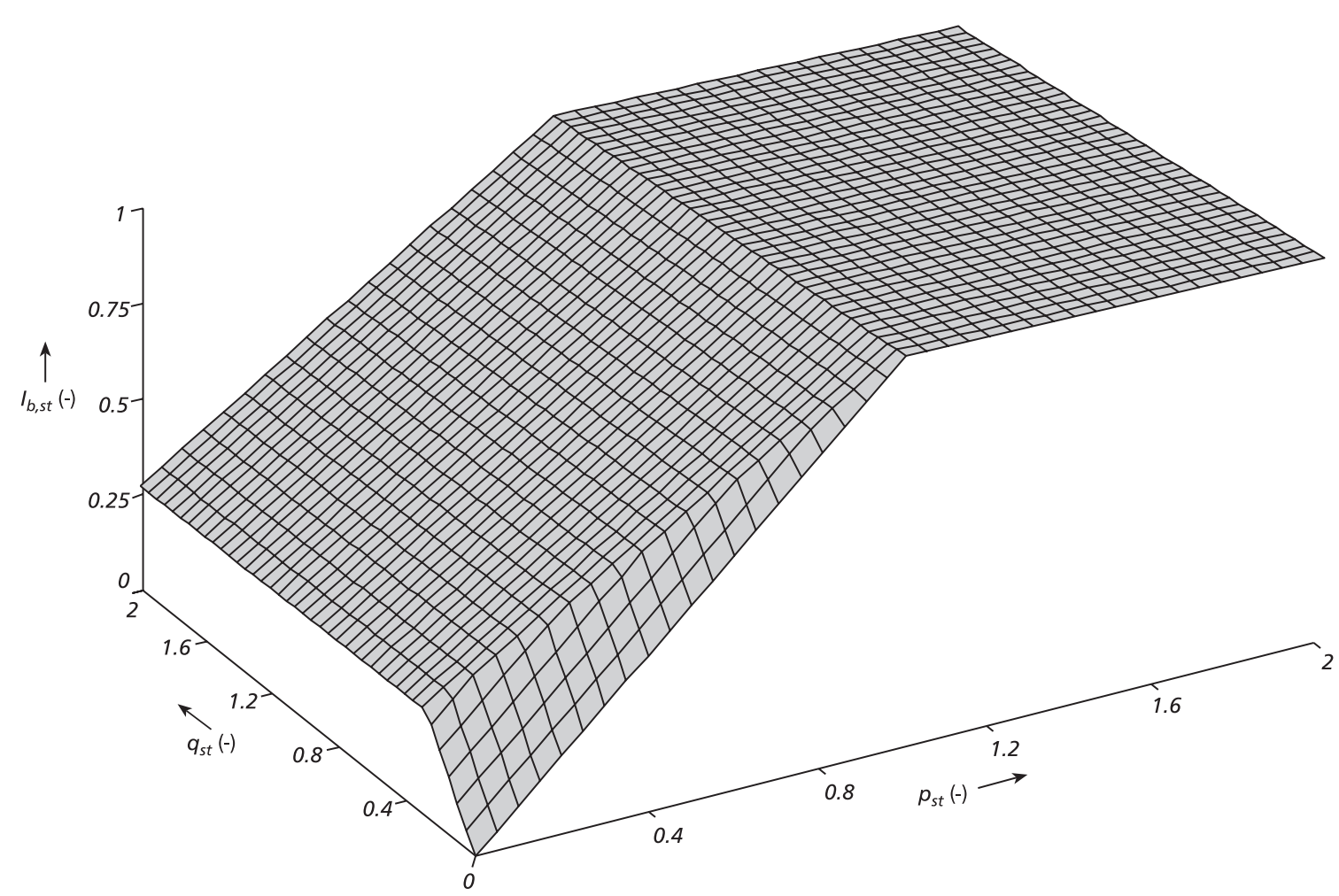

Fig. 6. Relation between $p_{\mathrm{st}}, q_{\mathrm{st}}$, and $i_{\mathrm{b}, \mathrm{st}}$ for Eq. (16), $a=0.28$. Note that $i_{\mathrm{b}, \mathrm{st}}=i_{\mathrm{b}} / m_{K_{p}(\mathbf{s})}$.

with $\delta$, a variable; and $I_{\mathrm{st}}(\Delta)$, the standardized actual infiltration (-) of a unit as a function of $\Delta$. From (19) it follows that $g$ should have the following properties:

$\left.\frac{\partial g\left[p_{\mathrm{st}}, q_{\mathrm{st}}\right]}{\partial p_{\mathrm{st}}}\right|_{\left(p_{\mathrm{st}}, q_{\mathrm{st}}\right)=(0,0)}=1,\left.\quad \frac{\partial g\left[p_{\mathrm{st}}, q_{\mathrm{st}}\right]}{\partial q_{\mathrm{st}}}\right|_{\left(p_{\mathrm{st}}, q_{\mathrm{st}}\right)=(0,0)}=1$.

In addition, Appendix A, Lemma 2, shows that:

$\lim _{\delta \rightarrow+\infty} E\left(I_{\mathrm{st}}(\Delta) \mid \Delta \geqslant \delta\right)=E\left(K_{\mathrm{st}}\left(\mathbf{s}_{i}\right)\right)$.

And from this it follows that $g$ should have the following properties:

$\lim _{p_{\mathrm{st}} \rightarrow+\infty} g\left[p_{\mathrm{st}}, q_{\mathrm{st}}\right]=1, \quad \lim _{q_{\mathrm{st}} \rightarrow+\infty} g\left[0, q_{\mathrm{st}}\right]=a$.

A function $h$ resulting in the properties of $g$ given in (20) and (22) is (Appendix B):

$h[x, d, b]=d \frac{1+b+\frac{x+b x}{d}-\sqrt{-4 b(1+b) \frac{x}{d}+\left((1+b)\left(1+\frac{x}{d}\right)\right)^{2}}}{2 b}$

with $b$ in the range $\langle-1, \infty\rangle$. Fig. 7 illustrates the shape of $g$ (17) using (23), with an example using a value of $a$ also used in Fig. 6, and rather low values for $b_{p}$ and $b_{q}$.
When $b_{p}$ and $b_{q}$ are increased, the surface approaches the surface represented by (16) (Fig. 6). In other words, $b_{p}$ and $b_{q}$ define how much 'lower' the surface is compared to the surface represented by (16), in the $p_{\text {st }}$ and $q_{\text {st }}$ directions respectively.

The results of a sensitivity analysis with $g$ in Fig. 8 are given using $\log$ transformed values of $b_{p}$ and $b_{q}$ since fitting these parameters to $G$ using field data results in an approximately lognormal distribution, as will be shown in Section 3. The sensitivity analysis shows that with a $p_{\text {st }}$ value greater than $q_{\mathrm{st}}$, typical for the first part of a rainstorm, $i_{\mathrm{b}, \mathrm{st}}$ calculated by $g\left(p_{\mathrm{st}}, q_{\mathrm{st}}\right)$ is more sensitive to changes of $b_{p}$ than to changes in other input parameters (Fig. 8A). Since infiltration in the area $(a)$ with runon from upstream cells is very low as a result of the small value of $q_{\mathrm{st}}$, resulting in a low sensitivity to changes in $b_{q}$. For a $p_{\text {st }}$ value less than the $q_{\text {st }}$ value, the opposite is true, and $i_{\mathrm{b}, \mathrm{st}}$ becomes also sensitive to changes in $b_{q}$ and $a$ (Fig. $8 \mathrm{~B}$ ).

\section{Case study: upscaling under steady state conditions}

\subsection{Study area and approach}

The aim of the case study is to test the upscaling techniques against field data, collected in the 'La Folie' catchment in the Ouvèze river basin, S. France, near 

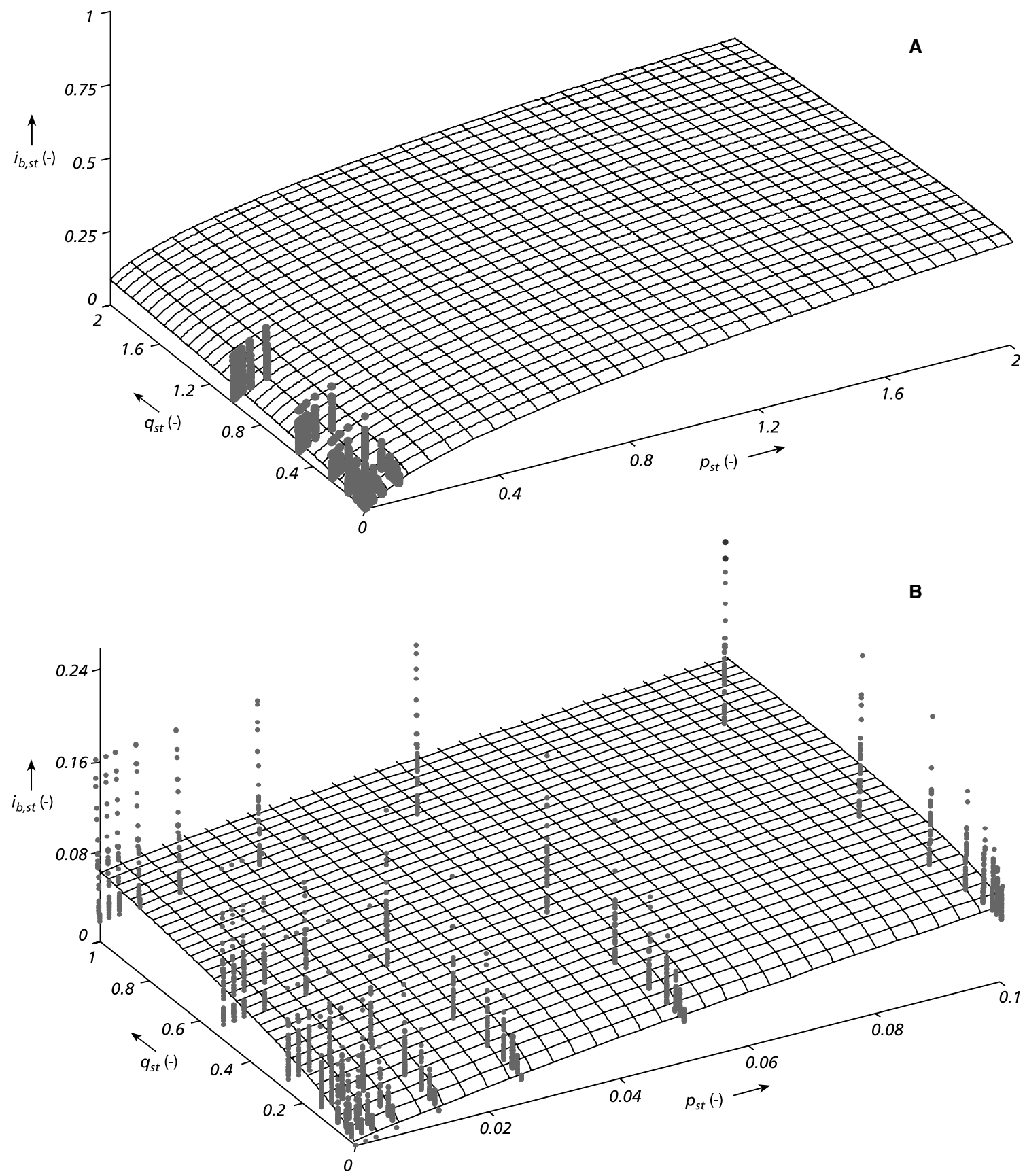

Fig. 7. Surface: relation between $q_{\mathrm{st}}, p_{\mathrm{st}}$, and $i_{\mathrm{b}, \mathrm{st}}$ for the upscaling technique $g, a=0.28$ (which is the same as in Fig. 6), $b_{p}=-0.88, b_{q}=-0.98$. Dots represent realizations of the Monte Carlo simulation to which $b_{p}$ and $b_{q}$ have been fitted. (A) Axes corresponding to Fig. 6; (B) cutoff axes. Note that $i_{\mathrm{b}, \mathrm{st}}=i_{\mathrm{b}} / m_{K_{p}(\mathbf{s})}$.

the village of Entrechaux (cf. [58]). This catchment, referred to as catchment $\mathrm{A}$, contains catchment $\mathrm{B}$ which is a single hillslope (Table 2).

Since all tests of the upscaling techniques (Fig. 9) calculate block infiltration from point-scale saturated conductivity, ring infiltrometer measurements are done to derive this point-scale saturated conductivity. For steady state conditions of rainfall, the stochastic upscaling technique described in Section 2.2 is used to upscale the point-scale values to block-scale (support $1 \mathrm{~m}^{2}$ ) actual infiltration. By comparing this calculated block-scale infiltration with measured values derived from rainfall simulation experiments, an evaluation is made how well the stochastic upscaling technique performs under steady state conditions. This is done in the sections below. The tests of the upscaling techniques with transient conditions (Fig. 9) are described in Section 4. 

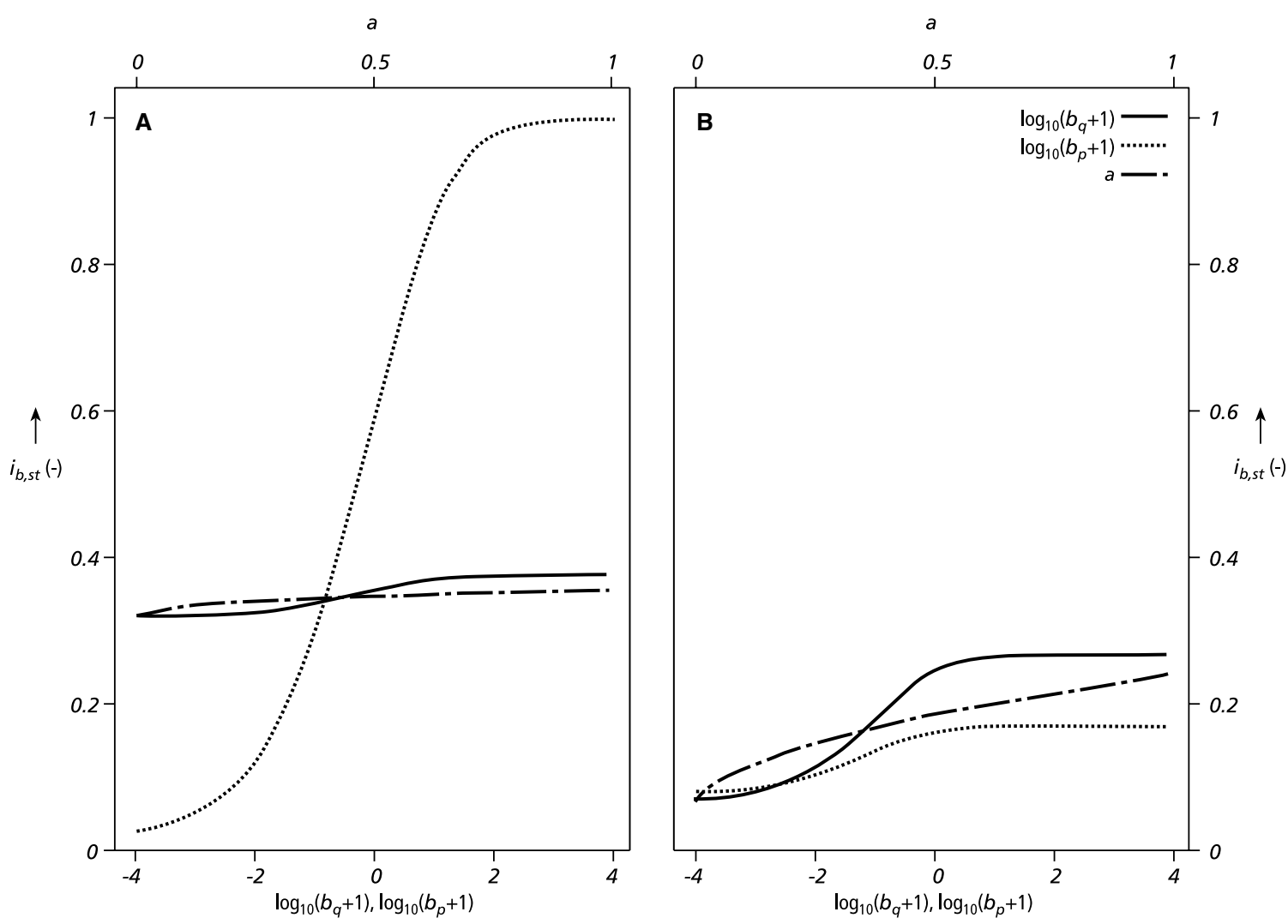

Fig. 8. Sensitivity analysis with $g$. Each line represents the change in $i_{\mathrm{b}, \mathrm{st}}\left(\right.$ i.e., $\left.g\left(p_{\mathrm{st}}, q_{\mathrm{st}}\right)\right)$ as a result of changing either $a, \log _{10}\left(b_{p}+1\right) \operatorname{or} \log _{10}\left(b_{q}+1\right)$, while keeping the other parameters constant at a standard value. For each parameter, this standard value is the average of the values on catchment B shown in Fig. 13. These are $a=0.22, \log _{10}\left(b_{q}+1\right)=-0.86, \log _{10}\left(b_{p}+1\right)=-1.15$. Upper horizontal axis, absolute values of $a$; lower horizontal axis, absolute values of $\log _{10}\left(b_{p}+1\right)$ and $\log _{10}\left(b_{q}+1\right)$. (A) $p_{\mathrm{st}}=1.4, q_{\mathrm{st}}=0.1 ;(\mathrm{B}) p_{\mathrm{st}}=0.1, q_{\mathrm{st}}=1.4$.

Table 2

Properties of catchment A and B

\begin{tabular}{lllll}
\hline Catchment & Area & Land use & Soil type (USDA) & Average slope (m/m) \\
\hline A & $0.43 \mathrm{~km}^{2}$ & Vineyards, grassland, forest & Loamy sands, sandy loams, silt loam & 0.25 \\
B & $7500 \mathrm{~m}^{2}$ & Vineyard & 2.780 & 0.042 \\
\hline
\end{tabular}

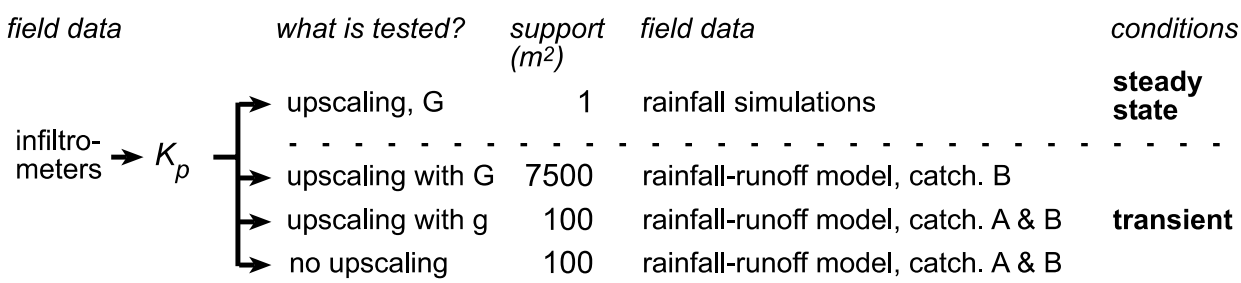

Fig. 9. Field measurements and tests of stochastic $(G)$ and deterministic $(g)$ upscaling techniques. Support size given of block actual infiltration.

\subsection{Field data}

Infiltration measurements were made with doublering infiltrometers in May and June 1997, in catchment A. The inner $(0.2 \mathrm{~m}$ diameter $)$ and outer $(0.4 \mathrm{~m}$ diameter) rings were driven $3-5 \mathrm{~cm}$ into the ground and smeared with cement. Water was applied to both inner and outer rings, keeping a constant head of $3 \mathrm{~cm}$. Infil- tration in the inner ring was recorded with a Mariotte bottle until $0.03 \mathrm{~m}$ of cumulative infiltration. Saturated conductivity $\left(K_{p}^{*}, \mathrm{~mm} / \mathrm{h}\right)$ was derived by fitting the $a_{\mathrm{g}}$ $(\mathrm{mm} / \mathrm{h})$ and $s\left(\mathrm{~mm} / \mathrm{h}^{0.5}\right)$ parameters in the equation $[44,45]$, assuming $a_{\mathrm{g}}=2 / 3 \cdot K_{p}^{*} \quad$ (Green-Ampt soil, $[44,45])$ :

$c=s \sqrt{t}+a_{\mathrm{g}} t$ 
with $c$, the cumulative infiltration $(\mathrm{mm})$ in the inner ring at time $t(\mathrm{~s})$. The probability distribution of the saturated conductivity derived from the results in Table 3 is regarded as lognormal, since (1) a Kolmogorov-Smirnov test rejected the hypothesis of a normal distribution, while a lognormal distribution was not rejected $(\alpha=0.05)$, and (2) a cumulative probability plot gives a rather good correspondence with a lognormal distribution. The mean of the values is large compared to results found in other studies (e.g., $[34,48,50,52,55])$, which can be explained by the occurrence of macro pores. Refs. $[14,31,60]$ found comparably large values, with macropores or cracks in the soil.

Also in catchment A, rainfall simulation experiments were done at random locations on cultivated land, in May-July, 1994-1997 (cf. [59]). For measuring infiltration at different rain intensities, multiple rainfall simulators were used (Table 4). Runoff was collected at the downstream border of the rectangular rainfall simulator plot, under a rainfall intensity that was kept constant during an experiment, until a constant rate of runoff was measured, representing a steady state situation of infiltration. For each experiment, $i_{\mathrm{b}, p}^{*}$ was calculated as the infiltration on the plot during the last part of the experiment.

Since the considerable variation in $i_{\mathrm{b}, p}^{*}$, as shown in Fig. 10, could not be explained by variation in soil type, other relations were evaluated for all rainfall simulation data together. Fig. 10 shows that the $i_{\mathrm{b}, p}^{*}$ values are much lower than the saturated conductivity measured with the ring infiltrometers, which was also found by [14]. The $i_{\mathrm{b}, p}^{*}$ values increase with rain intensity which was also found by other plot studies ([11,28,38,62], and Horton as calculated by [4]). Although the rainfall simulator experiments showed a correlation with unit kinetic energy of the rain $\left(r^{2}=0.46\right)$, it is not expected that removal of surface crusts, as suggested by [11], plays an important role in increasing $i_{\mathrm{b}, p}^{*}$ with rain intensity (cf., [59]).

\subsection{Method}

The approach followed to test the stochastic upscaling technique $G$ under steady state conditions involves two steps: (1) the point-scale saturated conductivity measured with the infiltrometers is used to calculate the block-scale (support $1 \mathrm{~m}^{2}$ ) actual infiltration, with the stochastic upscaling technique described in Section 2.2 , (2) to evaluate whether or not the field measurements corroborate the stochastic upscaling technique, a comparison is made between the calculated block-scale actual infiltration and the block-scale actual infiltration measured with the rainfall simulators.

In step one, the parameters describing the point-scale saturated conductivity $\left(K_{p}(\mathbf{s})\right.$, defined in Eqs. (3)-(7)) are needed. For the mean and the variance of $K_{p}(\mathbf{s})$, the values measured with the infiltrometers are used, $m_{K_{p}}=1004 \mathrm{~mm} / \mathrm{h}$ and $\sigma_{Z(\mathbf{s})}^{2}=7.73$ (Table 3). Since the semivariogram range parameter $a_{\mathrm{var}}$ (6) cannot be calculated from the limited number of infiltrometer measurements, this parameter will be calibrated. With the point-scale saturated conductivity as input, the stochastic upscaling technique $G$ is used to calculate representative actual infiltration $\left(I_{\mathrm{b}, p}, \mathrm{~mm} / \mathrm{h}\right)$ of rainfall simulation plots. This is done with a block of $1 \times 1 \mathrm{~m}$, representing the area of rainfall simulation plots, and a unit size $|u|$ of $0.2 \times 0.2 \mathrm{~m}$, representing the approximate area of ring infiltrometer measurements. Detailed elevation data are only available for catchment $\mathrm{B}$, so these data are used to derive runoff patterns needed in the stochastic upscaling technique. For each Monte Carlo loop, the local drain direction pattern is derived from the elevation model of a $1 \times 1 \mathrm{~m}$ plot at a random location on this hillslope.

Table 3

Summary statistics of saturated conductivity $\left(K_{p}^{*}, \mathrm{~mm} / \mathrm{h}\right)$ measured by ring infiltrometers

\begin{tabular}{llllll}
\hline & Mean & Median & Standard deviation & Coefficient of variation (\%) & Number of measurements \\
\hline$K_{p}^{*}$ & 1002 & 280 & 1502 & 150 & 18 \\
$\ln \left(K_{p}^{*}\right)$ & 5.081 & 5.629 & 2.780 & 55 & 18 \\
\hline
\end{tabular}

Table 4

Properties of rainfall simulators

\begin{tabular}{lllll}
\hline Simulator & Type & Rain intensity $(\mathrm{mm} / \mathrm{h})$ & UKE $\left(\mathrm{J} \mathrm{m}^{-2} \mathrm{~mm}^{-1}\right)$ & Plot area $\left(\mathrm{m}^{2}\right)$ \\
\hline 1 & s & $25-90$ & 13 & $1.0 \times 0.8$ \\
2 & s & $58-79$ & 13 & $2.1-2.6 \times 0.8-1.2$ \\
3 & s & $85-105$ & 17 & $0.6 \times 0.6$ \\
4 & d & $20-30$ & 7 & $0.4 \times 0.8$ \\
5 & s & $67-152$ & 7 & $0.4 \times 0.8$ \\
6 & d & $80-423$ & 23 & $0.14 \times 0.14$ \\
\hline
\end{tabular}

Type, type of rainfall generating mechanism—s: spray nozzles, d: drop-formers [2]; UKE, unit kinetic energy or kinetic energy applied to $1 \mathrm{~m}^{2}$ of the soil surface by $1 \mathrm{~mm}$ of artificial rain. 


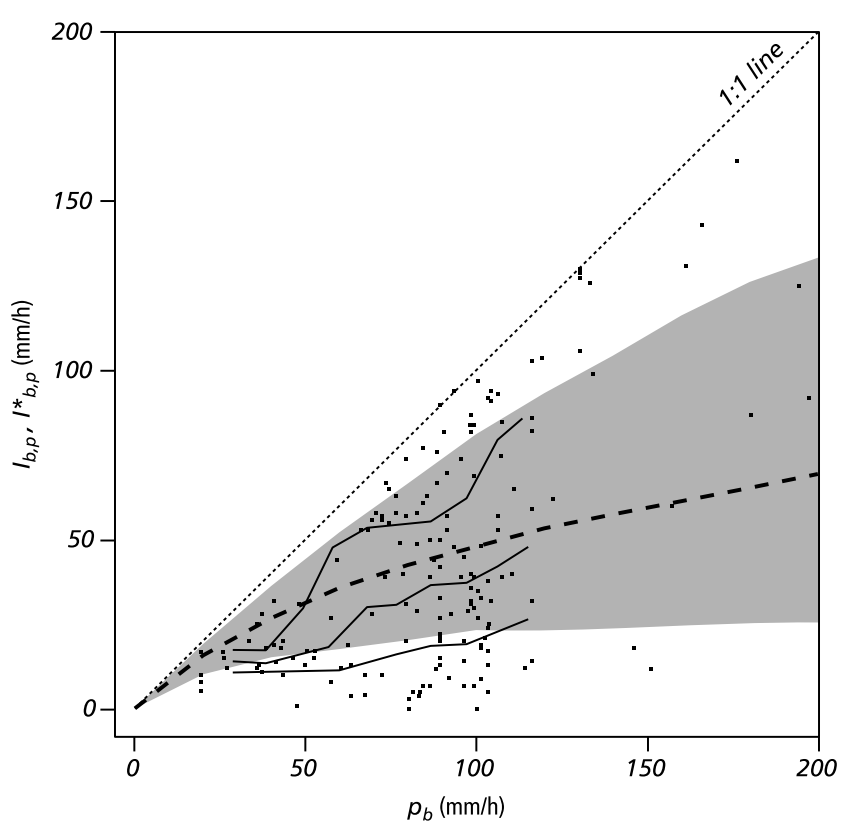

Fig. 10. Representative actual infiltration against rain intensity for plots. Dots: representative actual infiltration $\left(I_{\mathrm{b}, p}^{*}, \mathrm{~mm} / \mathrm{h}\right)$ derived from rainfall plot experiments $(n=173)$ against rain intensity $\left(p_{\mathrm{b}}, \mathrm{mm} / \mathrm{h}\right)$ applied with the rainfall simulator. Solid lines: first quartile, median and third quartile of $I_{\mathrm{b}, p}^{*}$, moving average with a width of the moving window of $50 \mathrm{~mm} / \mathrm{h}$. Dashed line: median of modelled representative actual infiltration $\left(I_{\mathrm{b}, p}, \mathrm{~mm} / \mathrm{h}\right)$ against net rain intensity $\left(p_{\mathrm{b}}, \mathrm{mm} / \mathrm{h}\right)$, grey area represents values between modelled first and third quartile.

Calibration of the semivariogram range parameter $a_{\mathrm{var}}$ is done as follows. The aim is to find the value of $a_{\text {var }}$ (6) resulting in the smallest deviation between the probability distribution of block actual infiltration $\left(I_{\mathrm{b}, p}^{*}\right)$, measured with the rainfall simulations, and the probability distribution $I_{\mathrm{b}, p}$ calculated with the stochastic upscaling technique, at all rain intensities. For each rainfall experiment, the upscaling technique estimates $I_{\mathrm{b}, p}$, at a rain intensity $p_{\mathrm{b}}$ (with $q_{\mathrm{b}}=0$ ) corresponding to the intensity applied during the rainfall experiment. This is done with 200 Monte Carlo loops for each rainfall experiment, resulting in a simulated distribution of saturated conductivity at different rain intensities, which could be plotted as dots just like the $i_{\mathrm{b}, p}^{*}$ values in Fig. 10, although it would contain $173 \times 200$ dots. The simulated and measured values are compared by making deciledecile plots of the measured distribution $I_{\mathrm{b}, p}^{*}$ and the simulated distribution $I_{\mathrm{b}, p}$, in three intervals $i$ of the rainfall intensity $p_{\mathrm{b}}$ : (1) $0-50$, (2) 50-100 and (3) $100-200 \mathrm{~mm} / \mathrm{h}$. The range parameter $a_{\text {var }}$ in (6) is calibrated using these decile-decile values by minimizing the sum of squares SS:

$\mathrm{SS}=\sum_{i=1}^{3}\left\{\sum_{j=1}^{9}\left(\phi_{i, j}-\phi_{i, j}^{*}\right)^{2}\right\}$

with $i$, the interval number of $p_{\mathrm{b}} ; j$, the decile number; $\phi_{i, j}$, the measured decile $(\mathrm{mm} / \mathrm{h}) ; \phi_{i, j}^{*}$, the modelled decile $(\mathrm{mm} / \mathrm{h})$. Calibration is done by a brute force technique calculating SS for $a_{\mathrm{var}}$ values of $0.4+0.1 * \alpha$, for $\alpha=$ $1,2, \ldots, 75$, selecting the $a_{\text {var }}$ value with the lowest value of SS. This results in a calibrated range parameter $a_{\mathrm{var}}$ of $1.2 \mathrm{~m}$, with a value for SS (Eq. (25)) of $3248 \mathrm{~mm}^{2} / \mathrm{h}^{2}$ (Fig. 11).

\subsection{Results and discussion}

Fig. 10 shows that, after calibration of the range parameter, the modelled distribution $I_{\mathrm{b}, p}$ for the rainfall plots fits well with the measured distribution $I_{\mathrm{b}, p}^{*}$, although the model overestimates percentile values at rain intensities in intervals 1 and 2, while it underestimates percentiles in interval 3 (Fig. 11). The differences between actual infiltration derived by rainfall simulation experiments and the upscaled values can be attributed to (1) measurement errors, (2) variation in saturated conductivity between soil types included in the rainfall simulation data set, which is not represented by the ring infiltrometer measurements since these were all done on silt loam soils, and (3) additional processes which are not represented by $G$, such as removal or formation of surface crusts.
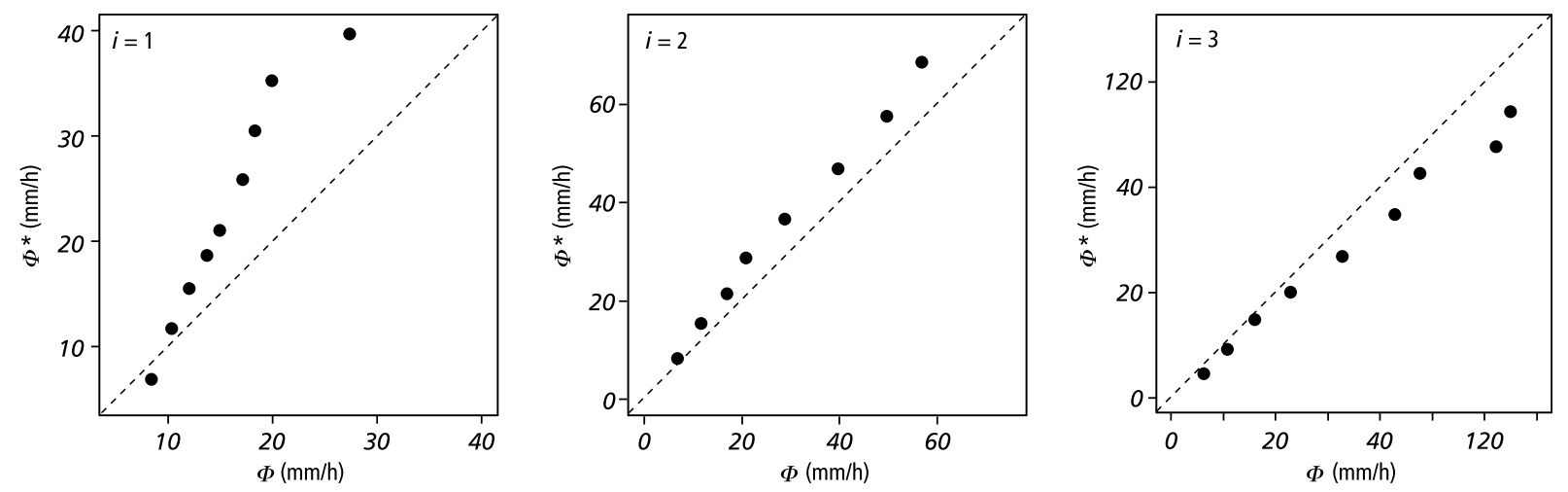

Fig. 11. Modelled $\left(\phi^{*}\right)$ against observed $(\phi)$ deciles for three intervals of rain intensity $\left(p_{\mathrm{b}}\right)$ of rainfall simulation experiments. Intervals: $i=1$, with $p_{\mathrm{b}}$ between 0 and $50 \mathrm{~mm} / \mathrm{h} ; i=2$, with $p_{\mathrm{b}}$ between 50 and $100 \mathrm{~mm} / \mathrm{h}, i=3$, with $p_{\mathrm{b}}$ between 100 and $200 \mathrm{~mm} / \mathrm{h}$. 
Although the calibrated range of $1.2 \mathrm{~m}$ cannot be verified with the field measurements presented here, it is a plausible value. Other researchers find scales of spatial variation in saturated conductivity at this support that is comparable. Experimental semivariograms of saturated conductivity at the soil surface given in [12,31, $34,37,49$ ] suggest that $50-100 \%$ of spatial variation occurs over distances smaller than 5-10 m.

\section{Case study: upscaling under transient conditions}

\subsection{The dynamic spatial rainfall-runoff model}

The application of the upscaling techniques for estimating the actual infiltration under transient situations will be evaluated with a dynamic spatial rainfall-runoff model. The upscaling techniques are used to calculate block actual infiltration from point-scale saturated conductivity, with blocks corresponding to model units of a rainfall-runoff model (Fig. 9). This approach is tested by comparing measured discharge and discharge modelled with the rainfall-runoff model using upscaled infiltration.

The rainfall-runoff model applied here discretises the time $(t, \mathrm{~s})$ in time steps of $5 \mathrm{~s}$ and uses grid cells of $10 \times 10 \mathrm{~m}$. For each time step and each grid cell the net rainfall is calculated as the rainfall minus interception, calculated according to [36]. Surface water that is not kept in a constant potential surface storage is routed as sheet flow over the steepest descend path between grid cells towards a ditches-network with channel flow, using the kinematic wave and the Manning equation [16,32]. Actual infiltration is calculated with an upscaling technique. The model runs in the PCRaster spatio-temporal modelling language [42].

Field data to derive model input parameters and variables for rainfall-runoff modelling were collected in catchment A and B, in 1997 and 1998 (Table 5, cf. [58]). Hydrographs and the cumulative discharge $\left(d_{\mathrm{m}}\right.$, $\mathrm{m}^{3}$ ) under Hortonian runoff was measured for catchment A and B. Errors in these measurements were estimated resulting in minimum $\left(d_{\mathrm{m}, \mathrm{min}}, \mathrm{m}^{3}\right)$ and maximum $\left(d_{\mathrm{m}, \max }, \mathrm{m}^{3}\right)$ values of cumulative discharge.
The upscaling techniques derive block actual infiltration, to be used in the rainfall-runoff model, from pointscale saturated conductivity. Since both the ring infiltrometer and the rainfall simulation measurements do not reveal a significant difference in saturated conductivity between fields, it is assumed that the parameters for the point-scale saturated conductivity derived from these measurements $\left(\sigma_{Z(\mathbf{s})}^{2}=7.73, a_{\mathrm{var}}=1.2 \mathrm{~m}\right)$ can be applied for both catchments. It is assumed that values of maximum infiltration higher than the saturated conductivity occurring at the start of a rainstorm as a result of the suction force in unsaturated soil can be ignored.

Three different approaches are followed (Fig. 9, transient conditions):

- 'upscaling with $G$, saturated conductivity is upscaled to a block consisting of a single hillslope. This approach is tested using catchment B consisting of one single hillslope only and the stochastic upscaling technique $G$. This is described in Section 4.2.

- 'upscaling with $g$ ', saturated conductivity is upscaled to blocks corresponding to grid cells of the rainfallrunoff model. This approach, described in Sections 4.3 and 4.4, is done with the deterministic upscaling technique $g$. It is tested for catchment A and B.

- 'no upscaling', with an actual infiltration for each grid cell in the rainfall-runoff model that equals the minimum value of the amount of water available for infiltration (net rain and runon) and $m_{K_{p}}(\mathbf{s})$, the expectation of $K_{p}(\mathbf{s})$.

\subsection{Upscaling to the support of a hillslope using $G$}

For rainfall-runoff models representing a catchment by a set of, internally homogeneous hillslopes (e.g., [56]), representative actual infiltration rates are needed for each hillslope. To test the applicability of the stochastic upscaling technique $G$ in such rainfall-runoff models, $G$ is used to upscale the estimates of saturated conductivity derived from the ring infiltrometer measurements to standardized actual infiltration $I_{\mathrm{b}, \mathrm{st}}(\mathrm{mm} / \mathrm{h})$ of one hillslope (catchment B).

Table 5

Source of parameter values for the rainfall-runoff model, cf. [58]

\begin{tabular}{lll}
\hline Parameter or variable & Source & $N$ \\
\hline Digital elevation model & Interpolation from elevation contours & - \\
Tillage direction & Field observations & All fields \\
Rain intensity $\left(p_{\mathrm{b}}\right)$ & Tipping bucket, $0.077 \mathrm{~mm} / \mathrm{tip}$ & 1 location \\
Vegetation cover & Field measurement of canopy area and photographs of canopy & Several in winter and summer \\
Maximum content of interception store & Throughfall measurements & 20 \\
Maximum surface storage & Based on field data and [29] & - \\
Catchment discharge & Flume with continuous pressure recorders & 1 per catchment \\
Manning's $n$ & {$[16]$} & - \\
\hline
\end{tabular}




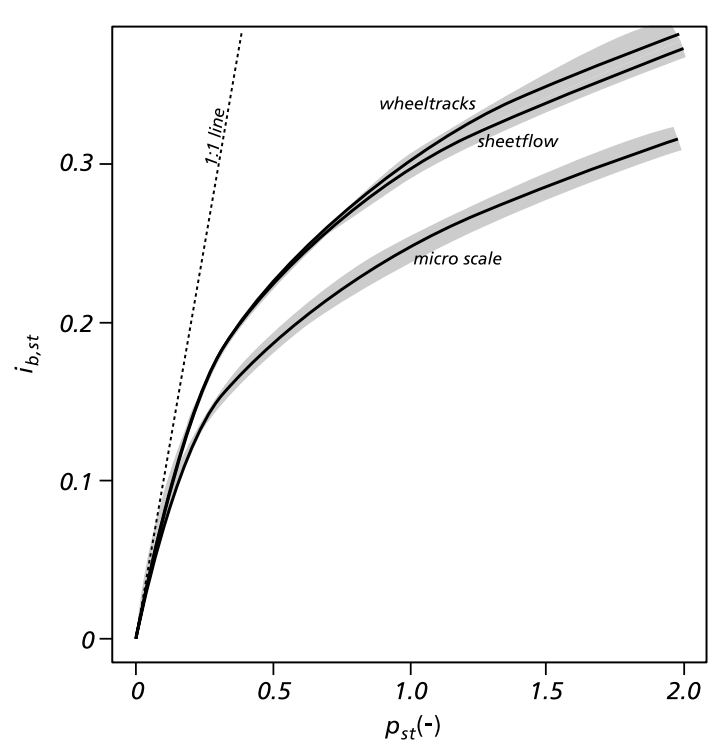

Fig. 12. Modelled standardized representative actual infiltration $\left(I_{\mathrm{b}, \mathrm{st}},-\right)$ as a function of standardized net rain intensity $\left(p_{\mathrm{st}},-\right)$ on catchment B. Three scenarios of runoff pattern. Line, median; grey area, values between modelled first and third quartile.

The standardized representative infiltration $\left(I_{\mathrm{b}, \mathrm{st}}\right)$ of the hillslope is calculated with $G$ using $|u|=0.2 \times 0.2 \mathrm{~m}$ and $m_{\mathrm{mc}}=200$, leading to stable estimates of the stochastic outcomes, for the three runoff patterns described in Section 2.1. Results are shown in Fig. 12. The values for the wheel tracks scenario are used to calculate the standardized representative actual infiltration for the block (i.e. the hillslope). For each $t$, the actual infiltration value is read from the $p_{\mathrm{st}}$-median $\left(I_{\mathrm{b}, \mathrm{st}}\right)$ at a $p_{\mathrm{st}}$ value corresponding to a value that is representative for the situation (intensity and spatial pattern) of runoff and infiltration at that moment, which is caused by rainfall at $t$ and over a period in the past. This representative $p_{\text {st }}$ value is calculated as the average net rain intensity over the period $\left[\max \left(t-l(t), t_{s}\right), t\right]$, with $l(t)$, the average travel time at $t$ of water from the edge of the hillslope to the outflow point, as calculated by the rainfall-runoff model, and $t_{s}$, the maximum of the $t-l(t)$ values calculated earlier during the rainstorm.

\subsection{Upscaling to the support of rectangular blocks using $g$, catchment $B$}

For rainfall-runoff models representing a catchment by a set of, internally homogeneous, grid cells, block actual infiltration rates are needed for each grid cell, where each grid cell is considered as a block. The applicability of the upscaling technique $g$ in such rainfallrunoff models is tested using data from catchment $\mathrm{B}$ (this section) and $\mathrm{A}$ (following section).

The parameter values $a, b_{p}$ and $b_{q}$ of the upscaling technique $g$ (17) for each block of catchment B are derived by fitting the transfer function of the deterministic upscaling technique $g$ to the outcome of the stochastic upscaling technique $G$. $G$ is run with flow with wheel tracks perpendicular to the general aspect of the field, which was the wheel track pattern observed during the simulated events. For each block, the following procedure is followed: (1) $G$ is run for 64 different combinations of values for $p_{\mathrm{st}}$ and $q_{\mathrm{st}}$ in the range of values actually occurring during a rainstorm, using $m_{\mathrm{mc}}=40$ samples per combination, resulting in $64 \times 40=2560$ realizations, (2) the parameter $a$ in the upscaling technique $g$ is assigned the value $E\left(\Omega_{\mathrm{b}}\right)$, (3) the remaining parameters $b_{p}$ and $b_{q}$ are fitted to the 2560 realizations of $i_{\mathrm{b}, \mathrm{st}}$ using least squares regression. Fig. 7 gives an example fit of $g$ to the realizations of the stochastic model $G$. Fig. 13 gives maps of the parameters for catchment B.

The upscaling technique $g$ parameterized in this way for each block, is used in the rainfall-runoff model to derive the standardized actual infiltration for each block and each timestep. For each $t(\mathrm{~s})$ in the model, a steady state situation of rainfall and runoff is assumed over a period $[t-\Delta t, t]$, with $\Delta t=100 \mathrm{~s}$, which is the estimated average travel time of water through a block. For each timestep at $t$, the value of $p_{\text {st }}$ (in g, Eq. (7)) is derived from the average value of the net rainfall over the period $[t-\Delta t, t]$. For each timestep at $t$, the runon at $t$ from sheet flow areas in upstream cells, excluding runon through ditches, is used for $q_{\mathrm{st}}$ (in g, Eq. (7)) in the upscaling technique $g$, assuming that $q_{\mathrm{st}}$ at $t$ represents the average situation of surface flow over $[t-\Delta t, t]$.

\subsection{Upscaling to the support of rectangular units using $g$, catchment $A$}

The approach followed in the previous section to find parameter values of $g$ by fitting to outcomes of $G$ is not feasible for larger catchments such as catchment A, since computer running times become unacceptably large when $G$ is used. An alternative approach is to search for relationships between the parameters of $g$ and data that are directly available in a rainfall-runoff modelling study. This allows applying $g$ in a rainfall-runoff modelling study without running $G$. This approach is followed here by using derivatives of the elevation model at the resolution of the grid cells in the rainfall-runoff model (blocks). Regression coefficients are searched for between the parameter values of $g$ as dependent variables and derivatives of the elevation model and parameters $\left(a_{\mathrm{var}}\right.$ and $\left.\sigma_{Z(\mathbf{s})}^{2}\right)$ describing the spatial probability distribution of the point-scale saturated conductivity (3)-(7) as independent variables. These regressions are defined for each of the three runoff patterns Pattern $_{p}$ (Section 2.1). For each runoff pattern, the regression coefficients are derived from catchment B as described below, and applied to catchment $\mathrm{A}$ to find $a, b_{p}$, and $b_{q}$ for each block of this catchment. 

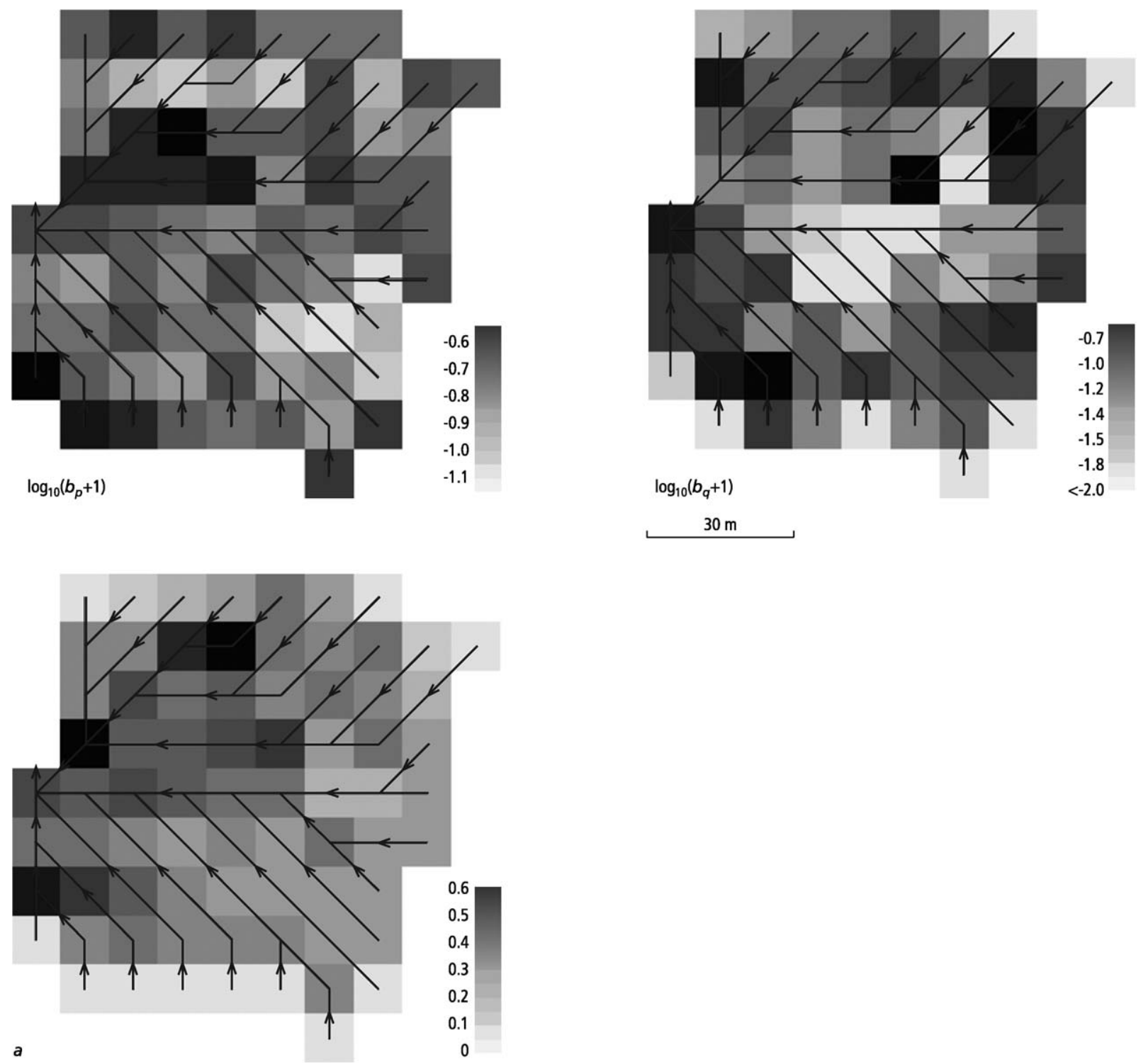

Fig. 13. Maps with $a, \log _{10}\left(b_{p}+1\right)$ and $\log _{10}\left(b_{q}+1\right)$ values on catchment $\mathrm{B}$, derived with the scenario with wheel tracks perpendicular to the general aspect of the field and $a_{\mathrm{var}}=1.25, \sigma_{Z(\mathrm{~s})}^{2}=7.73$, which are the values determined by the field measurements.

Dependent variables: in order to find parameter values of $g$ to serve as dependent variables in the regressions, $G$ is run with different combinations of inputs: (1) three different values of the semivariogram range parameter $a_{\mathrm{var}}=1.25,2.5$, and $5 \mathrm{~m}$, and (2) three different values of $\sigma_{Z(\mathbf{s})}^{2}=0.48,1.93$, and 7.73 . For each block on catchment $\mathrm{B}$, this resulted in $3 \times 3=9$ scenarios of $G$. For each of these scenarios, and for each block, the parameter values of $g$ are fitted to the outcomes of $G$ resulting in values of $a, b_{p}$ and $b_{q}$ for each scenario and for each block. Fitting is done using the approach as described in Section 4.3.

Independent variables: for each block (i.e., grid cell) of catchment B, the following derivatives of the digital elevation model at that resolution are calculated: the slope $(\mathrm{m} / \mathrm{m})$ at the block, derived from a window of $3 \times 3$ units using the third-order finite difference method of [27,51], the catchment area $\left(\mathrm{m}^{2}\right)$ of the block, which is the area of the block itself plus the blocks upstream over the local drain direction network derived with the 8-point pour algorithm [10], the planform and the profile curvature, which is the curvature transverse to the slope and in the direction of the slope, respectively. The curvature values, derived from a $3 \times 3$ window of blocks [63], have a positive value for a convex slope, and a negative value for a concave form of the slope. Finally, the slope perpendicular to the ploughing direction is calculated, which is the topographical slope perpendicular to the ploughing direction divided by the slope parallel to the ploughing direction.

Multiple linear regressions are done between $a$, $\log _{10}\left(b_{p}+1\right)$ and $\log _{10}\left(b_{q}+1\right)$ as dependent variables 
and the derivatives of the elevation model, $\sigma_{Z(\mathbf{s})}^{2}$ and $a_{\mathrm{var}}$ as independent variables. Log transformed variables were used when $\log$ transformed values were closer to a normal distribution than untransformed values, based on visual interpretation of histograms. For the multiple regressions, a backward elimination procedure was followed using the $C_{p}$ statistic as a criterion for dropping variables in each regression [20]. An inspection of the $C_{p}$ plot for all possible regressions [20] confirmed for all regressions the choice of variables derived by the backward elimination procedure.

Although interpretation of the results in Table 6 is difficult, some conclusions can be drawn. The multiple correlation coefficients for the regressions are between 0.25 and 0.70 , which means that the variation in the input parameters of the deterministic upscaling technique can partly be explained with derivatives of a digital elevation model at the resolution of the blocks and parameters describing the spatial probability distribution of $K_{p}(\mathbf{s})$. For the parameter $a$, the standardized regression coefficients have the highest absolute value for the catchment area. This is because the value $a$ is mainly determined by the number of units at the edge of a block receiving inflow from neighbouring blocks. For blocks near the edge of the hillslope, the number of units receiving inflow is low compared to the other blocks since the blocks near the edge have a limited (or zero) number of upstream neighbour blocks. The correlations between $a$ and the planform curvature are always positive, which can be explained by a divergent flow pattern with a convex slope and a convergent flow pattern with a concave slope. With convergent flow, $a$ will be smaller than with divergent flow. The coefficients of the multiple regression for $b_{p}$ and $b_{q}$ are negative for $\sigma_{Z(\mathbf{s})}^{2}$ and $a_{\mathrm{var}}$. In addition, a number of derivatives of the elevation model are significant variables in the regressions for $b_{p}$ and $b_{q}$.

Fig. 14 illustrates the sensitivity of $g\left(p_{\mathrm{st}}, q_{\mathrm{st}}\right)$ (i.e. $\left.i_{\mathrm{b}, \mathrm{st}}\right)$ to changes of the independent variables in the multiple regression. For the derivatives of the digital elevation model, it shows that $i_{\mathrm{b}, \mathrm{st}}$ is most sensitive to changes in the catchment area of a block, while planform curvature and slope of a block have an additional important effect for the case of large amounts of runoff and low amounts of rain (Fig. 14B).

For application in the transient rainfall-runoff model for catchment $\mathrm{A}$, the attributes used as independent variables in the multiple regression and the coefficients in Table 6 are used to estimate $i_{\mathrm{b}, \mathrm{st}}$ with $g$ for each block of catchment A. On catchment A, the upscaling technique $g$ is used in the same way as on catchment B to calculate $i_{\mathrm{b}, \mathrm{st}}$ in the rainfall-runoff model, for each timestep (see Section 4.3).

Table 6

Coefficients for multiple linear regression with parameters of the stochastic upscaling technique as dependent variables and derivatives of the digital elevation model, $\sigma_{Z(\mathbf{s})}^{2}$, and $a_{\mathrm{var}}$ as independent variables, catchment $\mathrm{B}$, three scenarios: sheet flow, flow with microscale variation and flow with wheel tracks

\begin{tabular}{|c|c|c|c|c|c|c|c|c|c|}
\hline & Int & Slope & $\begin{array}{l}\text { Catchment } \\
\text { area }\left(\log _{10}\right)\end{array}$ & $\begin{array}{l}\text { Planform } \\
\text { curvature }\end{array}$ & $\begin{array}{l}\text { Profile } \\
\text { curvature }\end{array}$ & $\begin{array}{l}\text { Slope perpendicular } \\
\text { to ploughing } \\
\text { direction }\left(\log _{10}\right)\end{array}$ & $\sigma_{Z(\mathbf{s})}^{2}$ & $a_{\mathrm{var}}$ & $r^{2}$ \\
\hline \multicolumn{10}{|l|}{ Sheet } \\
\hline$a$ & $\begin{array}{l}-0.35 \\
-1.4\end{array}$ & $\begin{array}{l}1.2 \\
0.094\end{array}$ & $\begin{array}{l}0.29 \\
0.50\end{array}$ & $\begin{array}{l}14 \\
0.14\end{array}$ & $\begin{array}{l}\text { n.s. } \\
\text { n.s. }\end{array}$ & $\begin{array}{l}\text { n.s. } \\
\text { n.s. }\end{array}$ & $\begin{array}{l}- \\
-\end{array}$ & - & 0.39 \\
\hline $\log _{10}\left(b_{p}+1\right)$ & $\begin{array}{l}1.25 \\
0.66\end{array}$ & $\begin{array}{l}-4.1 \\
-0.045\end{array}$ & $\begin{array}{l}0.72 \\
0.17\end{array}$ & $\begin{array}{l}\text { n.s. } \\
\text { n.s. }\end{array}$ & $\begin{array}{l}\text { n.s. } \\
\text { n.s. }\end{array}$ & $\begin{array}{l}\text { n.s. } \\
\text { n.s. }\end{array}$ & $\begin{array}{l}-0.45 \\
-0.74\end{array}$ & $\begin{array}{l}-0.14 \\
-0.12\end{array}$ & 0.59 \\
\hline $\log _{10}\left(b_{q}+1\right)$ & $\begin{array}{l}-0.025 \\
-0.021\end{array}$ & $\begin{array}{l}3.74 \\
0.065\end{array}$ & $\begin{array}{l}-0.32 \\
-0.12\end{array}$ & $\begin{array}{l}40 \\
0.083\end{array}$ & $\begin{array}{l}-266 \\
-0.34\end{array}$ & $\begin{array}{l}\text { n.s. } \\
\text { n.s. }\end{array}$ & $\begin{array}{l}-0.13 \\
-0.34\end{array}$ & $\begin{array}{l}-0.049 \\
-0.065\end{array}$ & 0.25 \\
\hline \multicolumn{10}{|l|}{ Microscale } \\
\hline$a$ & $\begin{array}{l}0.0090 \\
0.29\end{array}$ & $\begin{array}{l}\text { n.s. } \\
\text { n.s. }\end{array}$ & $\begin{array}{l}0.036 \\
0.51\end{array}$ & $\begin{array}{l}1.7 \\
0.13\end{array}$ & $\begin{array}{l}\text { n.s. } \\
\text { n.s. }\end{array}$ & $\begin{array}{l}\text { n.s. } \\
\text { n.s. }\end{array}$ & $\begin{array}{l}- \\
-\end{array}$ & $\begin{array}{l}- \\
-\end{array}$ & 0.38 \\
\hline $\log _{10}\left(b_{p}+1\right)$ & $\begin{array}{l}1.0 \\
0.55\end{array}$ & $\begin{array}{l}-2.3 \\
-0.026\end{array}$ & $\begin{array}{l}0.71 \\
0.17\end{array}$ & $\begin{array}{l}-27 \\
-0.037\end{array}$ & $\begin{array}{l}37 \\
0.031\end{array}$ & $\begin{array}{l}\text { n.s. } \\
\text { n.s. }\end{array}$ & $\begin{array}{l}-0.48 \\
-0.82\end{array}$ & $\begin{array}{l}-0.077 \\
-0.066\end{array}$ & 0.70 \\
\hline $\log _{10}\left(b_{q}+1\right)$ & $\begin{array}{l}-0.55 \\
-0.96\end{array}$ & $\begin{array}{l}1.4 \\
0.052\end{array}$ & $\begin{array}{l}\text { n.s. } \\
\text { n.s. }\end{array}$ & $\begin{array}{l}\text { n.s. } \\
\text { n.s. }\end{array}$ & $\begin{array}{l}-44 \\
-0.12\end{array}$ & $\begin{array}{l}\text { n.s. } \\
\text { n.s. }\end{array}$ & $\begin{array}{l}-0.14 \\
-0.75\end{array}$ & $\begin{array}{l}-0.058 \\
-0.16\end{array}$ & 0.61 \\
\hline \multicolumn{10}{|l|}{ Wheel tracks } \\
\hline$a$ & $\begin{array}{l}-0.24 \\
-2.0\end{array}$ & $\begin{array}{l}1.6 \\
0.27\end{array}$ & $\begin{array}{l}0.14 \\
0.50\end{array}$ & $\begin{array}{l}6.7 \\
0.13\end{array}$ & $\begin{array}{l}\text { n.s. } \\
\text { n.s. }\end{array}$ & $\begin{array}{l}0.016 \\
0.15\end{array}$ & $\begin{array}{l}- \\
-\end{array}$ & $\begin{array}{l}- \\
-\end{array}$ & 0.52 \\
\hline $\log _{10}\left(b_{p}+1\right)$ & $\begin{array}{l}1.5 \\
0.76\end{array}$ & $\begin{array}{l}\text { n.s. } \\
\text { n.s. }\end{array}$ & $\begin{array}{l}0.63 \\
0.14\end{array}$ & $\begin{array}{l}\text { n.s. } \\
\text { n.s. }\end{array}$ & $\begin{array}{l}33 \\
0.025\end{array}$ & $\begin{array}{l}0.13 \\
0.040\end{array}$ & $\begin{array}{l}-0.49 \\
-0.79\end{array}$ & $\begin{array}{l}-0.15 \\
-0.12\end{array}$ & 0.65 \\
\hline $\log _{10}\left(b_{q}+1\right)$ & $\begin{array}{l}-0.19 \\
-0.20\end{array}$ & $\begin{array}{l}4.4 \\
0.093\end{array}$ & $\begin{array}{l}-0.23 \\
-0.10\end{array}$ & $\begin{array}{l}49 \\
0.12\end{array}$ & $\begin{array}{l}-157 \\
-0.24\end{array}$ & $\begin{array}{l}-0.079 \\
-0.048\end{array}$ & $\begin{array}{l}-0.13 \\
-0.43\end{array}$ & $\begin{array}{l}-0.050 \\
-0.080\end{array}$ & 0.29 \\
\hline
\end{tabular}

Upper values are coefficients for non-standardized independent and dependent variables, lower values are coefficients for independent and dependent variables standardized to one standard deviation (sometimes called beta weights). 'Int', intercept; $r$ is multiple correlation coefficient; n.s., nonsignificant (dropped variables); - not used. 

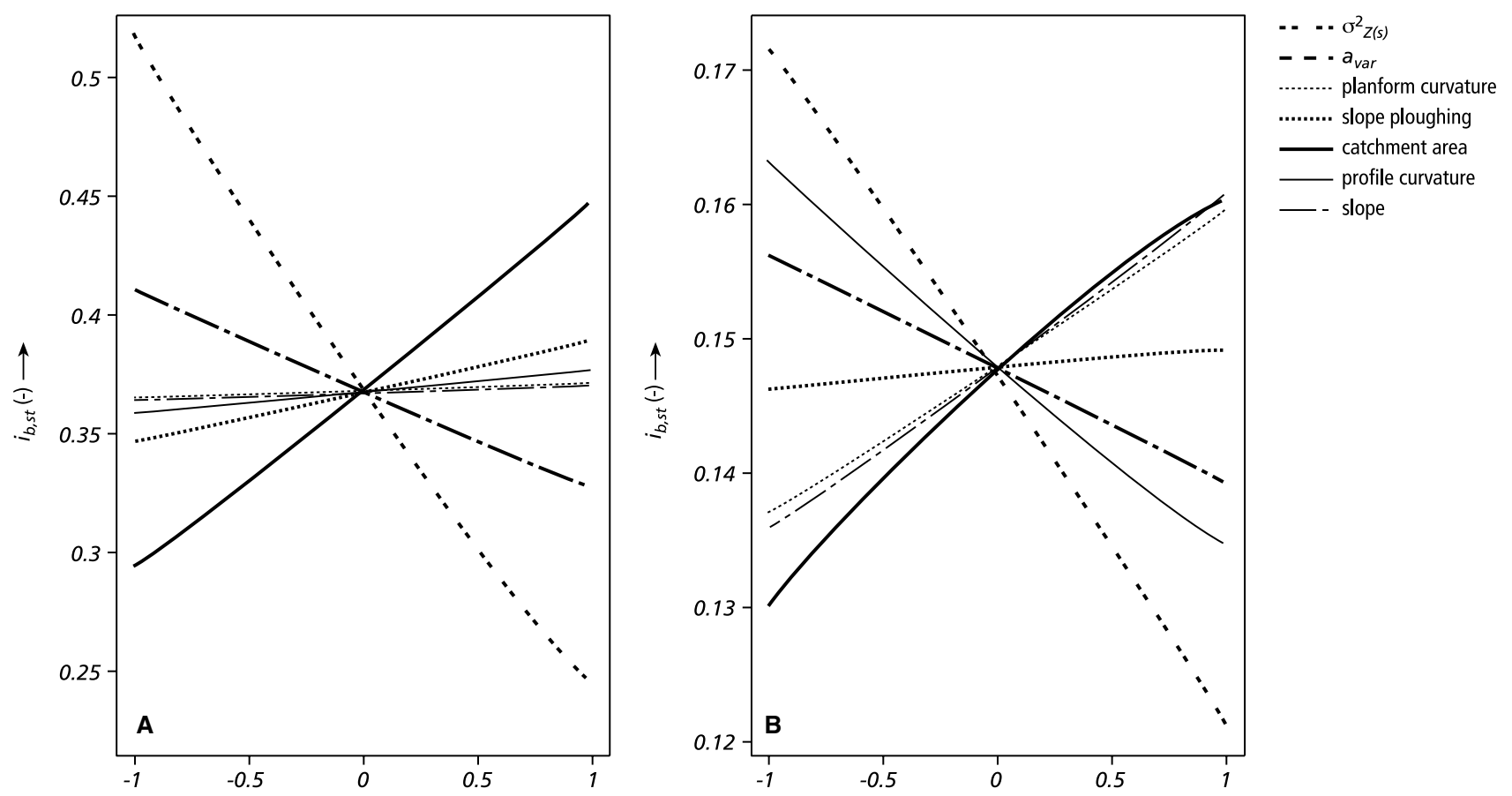

Fig. 14. Sensitivity analysis with the multiple regression analysis for flow with wheel tracks as input to the upscaling technique $g$. The value of $i_{\mathrm{b}, \mathrm{st}}$ (i.e., $\left.g\left(p_{\mathrm{st}}, q_{\mathrm{st}}\right)\right)$ is derived by calculating the input parameters $a, b_{p}, b_{q}$ with the regression coefficients of Table 6 , for flow with wheel tracks. Each line represents the change in $i_{\mathrm{b}, \mathrm{st}}$ as a result of changing one of the independent variables in the regression. For the derivatives of the elevation model, a value of 0 at the $x$-axis represents the average value, while a value of $1 /-1$ represents the average value plus/minus one standard deviation of the values on the hillslope. For $\sigma_{Z(\mathbf{s})}^{2}$, and $a_{\mathrm{var}}$, a value 0 represents the measured mean value and $1 /-1$ represents this measured mean value plus or minus 1. 'Slope ploughing' refers to the slope perpendicular to the ploughing direction. The variables slope ploughing and catchment area were $\log _{10}$ transformed. (A) $p_{\mathrm{st}}=1.4, q_{\mathrm{st}}=0.1 ;$ (B) $p_{\mathrm{st}}=0.1, q_{\mathrm{st}}=1.4$.

\subsection{Results and discussion of the transient simulations}

Transient simulations are done following the three different approaches referred to as 'upscaling with $G$ ', 'upscaling with $g$ ', and 'no upscaling' (Fig. 9). Runs referred to as 'no calibration' are done with a value for $m_{K_{p}(\mathbf{s})}$ derived from the saturated conductivity measured with ring infiltrometres, with $m_{K_{p}(s)}=1004 \mathrm{~mm} / \mathrm{h}$. These runs do not involve calibration of any of the parameters. For comparison, runs are done with $m_{K_{p}(s)}$ found by calibration, minimizing the mean square error (MSE):

$\operatorname{MSE}=\frac{\sum_{e=1, \ldots, n}\left(l_{e}^{2}\right)}{n}$

with $n$, the number of events measured for the catchment, where $l_{e}=\log _{10}\left(d_{s}+0.1\right)-\log _{10}\left(d_{m}+0.1\right)$, with $d_{\mathrm{s}}$, the simulated cumulative discharge at the outflow point $\left(\mathrm{m}^{3}\right)$, and $d_{\mathrm{m}}$, the measured cumulative discharge $\left(\mathrm{m}^{3}\right)$. The results are interpreted using the values of MSE (Fig. 15) and scatterplots between measured and simulated cumulative discharge (Figs. 16-19). For most approaches, the shape of the hydrographs corresponded rather well with measured hydrographs. A further evaluation of the shape of the hydrograph is not done here, since parameters determining the shape of the hydrograph (e.g., Manning's roughness coefficient) were not calibrated.
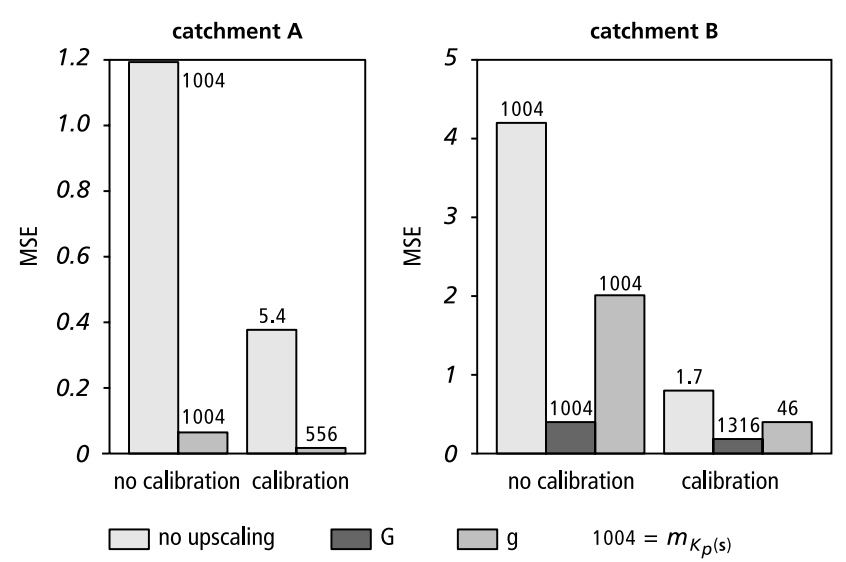

Fig. 15. Mean square error (MSE, Eq. (26)) of cumulative discharge. Three approaches are shown: no upscaling, without the use of an upscaling technique; $G$, using the stochastic upscaling technique $G ; g$, using the deterministic upscaling technique $g$. Value of $m_{K_{p}(\mathrm{~s})}(\mathrm{mm} / \mathrm{h})$ given above each of the bars.

The results of the 'no upscaling' approach are worse compared to the approaches using an upscaling technique. Without calibration, the 'no upscaling' approach results in zero discharge from catchment $\mathrm{B}$, while the simulated discharge from catchment $\mathrm{A}$ is caused by channel precipitation only, resulting in an underestimation of cumulative discharge. After calibration of $m_{K_{p}(\mathbf{s})}$, 

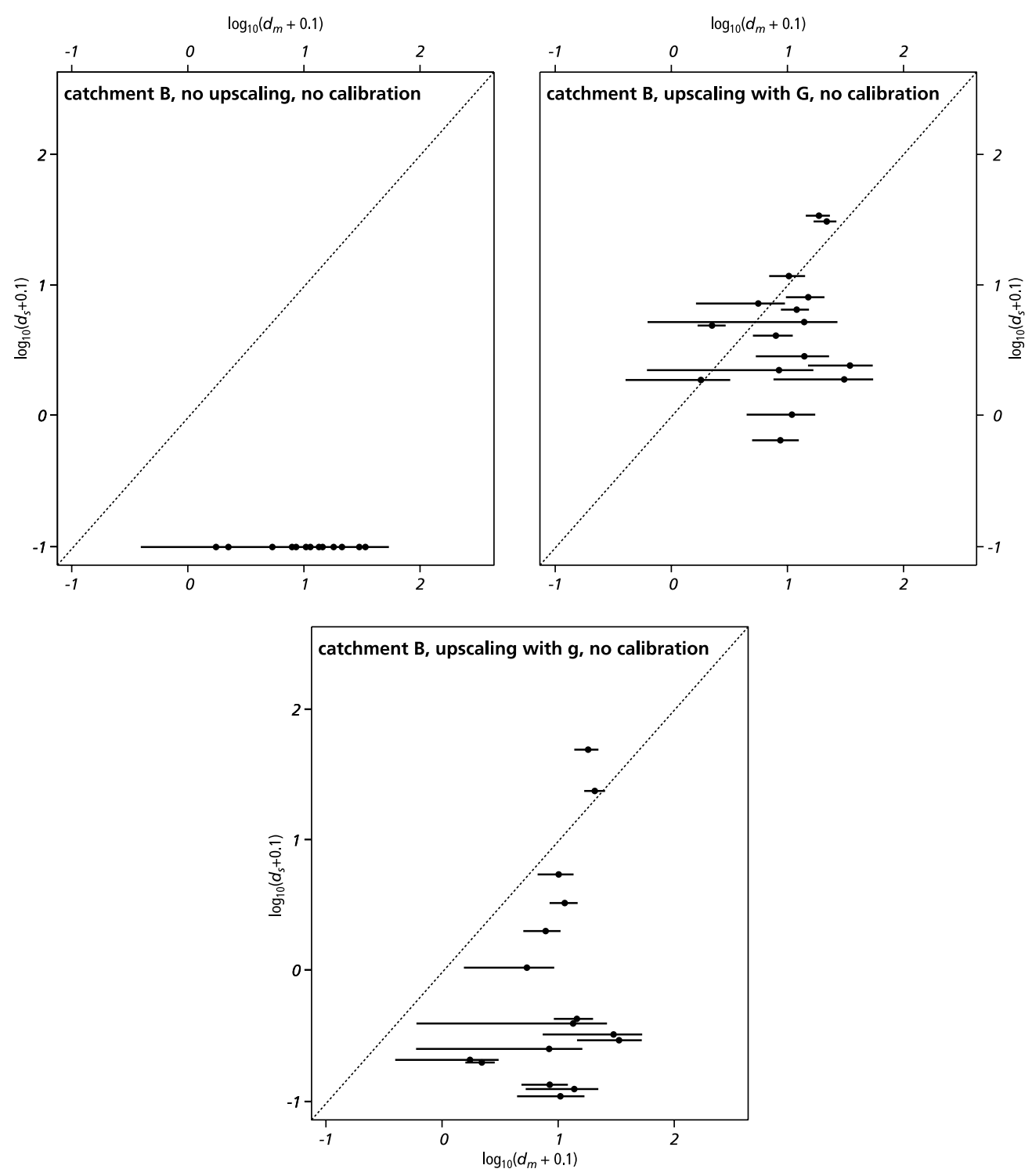

Fig. 16. Catchment B, no calibration of $m_{K_{p}(\mathrm{~s})}$. Dots: simulated $\left(d_{\mathrm{s}}, \mathrm{m}^{3}\right)$ against measured $\left(d_{\mathrm{m}}, \mathrm{m}^{3}\right)$ cumulative discharge. Horizontal lines indicate measurement error, with endpoints of each line representing $d_{\mathrm{m}, \min }$ and $d_{\mathrm{m}, \max }$ of the measured discharge.

the MSE values for the 'no upscaling' approach decrease, but remain greater than these for the approaches using an upscaling technique. Also, calibrated $m_{K_{p}(\mathbf{s})}$ values for the 'no upscaling' approach are at least $10^{2}$ times lower than the value of $m_{K_{p}}(\mathbf{s})$ measured with ring infiltrometres, as shown in Fig. 15. This discrepancy between measured and calibrated $m_{K_{p}(\mathbf{s})}$ indicates that the 'no upscaling' approach does not represent all processes. The stochastic upscaling technique $G$ applied to catchment B, calculating representative actual infiltration for the hillslope as a whole, seems to perform well in the sense that it results in simulated cumulative discharge in the same order of magnitude as measured cumulative discharge. This, and the other results for catchment B should be interpreted with care, due to the high measurement errors in cumulative dis- charge as shown by the large differences between $d_{\mathrm{m}, \min }$ and $d_{\mathrm{m}, \max }$ in Figs. 16 and 17.

The deterministic upscaling technique $g$ applied to catchment B, calculating block actual infiltration for each model unit in the rainfall-runoff model, results in an underestimation of cumulative discharge when $m_{K_{p}(\mathrm{~s})}$ is not calibrated. This is not the case when upscaling technique $g$ is applied to catchment A. Without calibration, the approach using $g$ is capable to give a good estimate of measured cumulative discharge, as shown in Fig. 18 and the relatively low values of MSE for this approach in Fig. 15. After calibration of $m_{K_{p}(\mathbf{s})}$, the MSE value for upscaling technique $g$ decreases, both on catchment $\mathrm{A}$ and $\mathrm{B}$.

Although the data sets are relatively small and prone to measurement errors, the case study provides valuable 

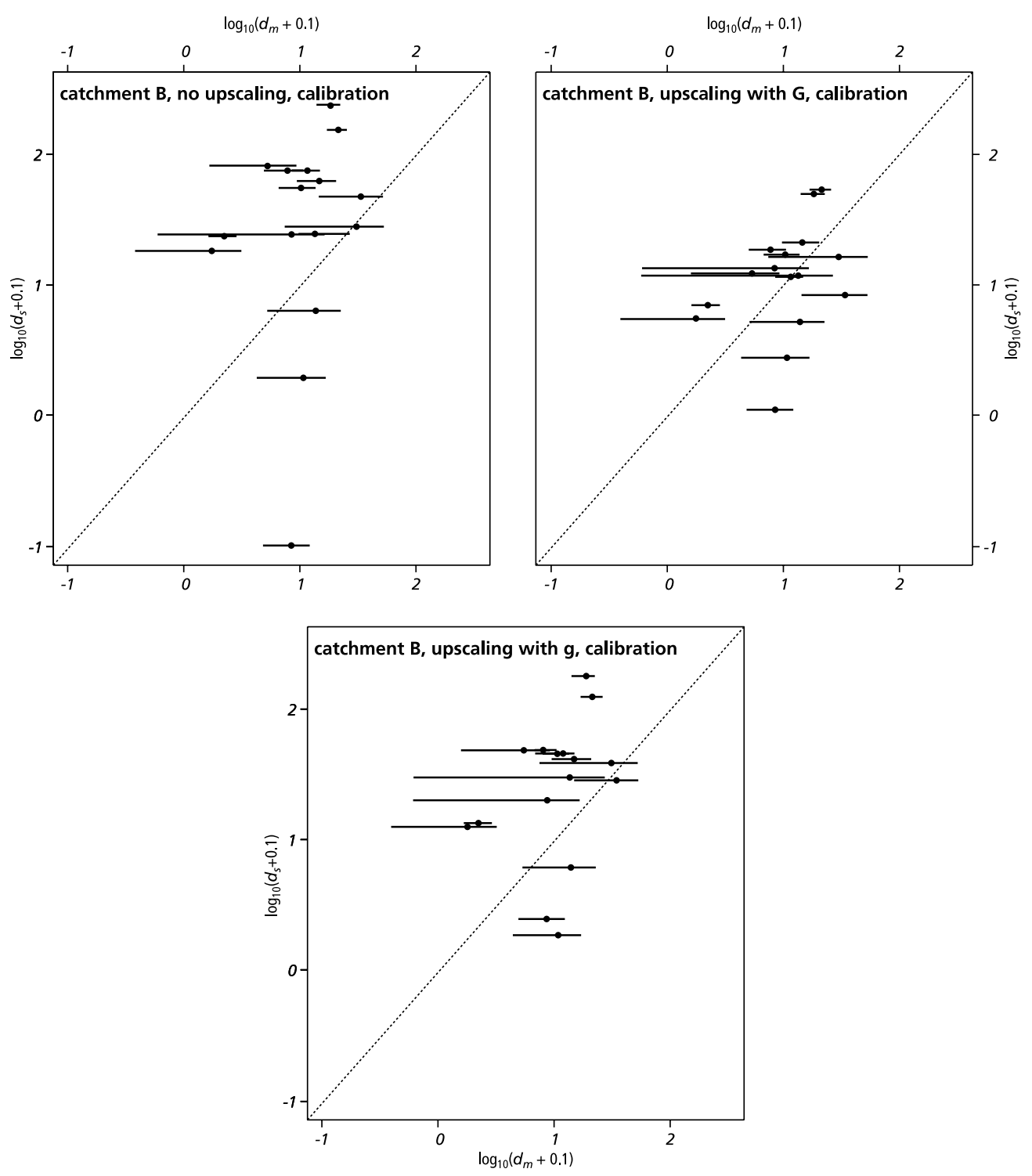

Fig. 17. Catchment B, calibration of $m_{K_{p}}(\mathrm{~s})$. Dots: simulated $\left(d_{\mathrm{s}}, \mathrm{m}^{3}\right)$ against measured $\left(d_{\mathrm{m}}, \mathrm{m}^{3}\right)$ cumulative discharge. Horizontal lines indicate measurement error, with endpoints of each line representing $d_{\mathrm{m}, \min }$ and $d_{\mathrm{m}, \max }$ of the measured discharge.

insight in the performance of the approaches. Without upscaling technique, it seems impossible to provide good estimates of cumulative discharge, even by calibrating $m_{K_{p}(\mathbf{s})}$. Both upscaling techniques described here improve the results regarding the prediction of cumulative discharge. The upscaling technique $g$ seems to be applicable for larger catchments such as catchment $\mathrm{A}$, even without calibration of $m_{K_{p}(\mathbf{s})}$. The results for catchment B need to be interpreted with care due to measurement errors, but $G$ seems to perform slightly better than $g$.

Both the upscaling techniques $G$ and $g$ are applied in a transient model under the assumption of a steady state situation of rain, runoff and infiltration over a certain time interval, for each timestep. The results presented do not reject this assumption, although the somewhat bad results for catchment B may be caused by this con- ceptual restriction. Further research using different sizes of blocks needs to be done to evaluate this assumption, and to evaluate both approaches regarding their usefulness in transient rainfall-runoff modelling. Testing the approaches with other data sets is also important because the large values for the average and the skewness of the distribution of saturated conductivity $\left(K_{p}(\mathbf{s})\right)$, found by ring infiltrometer measurements in this research area, is not representative for many other catchments.

The upscaling methods described here suffer from some weaknesses that need to be resolved. The first weakness is the assumption that spatial variation in net rain $\left(p_{\text {st }}\right)$ within a block is not taken into account, while it is expected to have effect on block actual infiltration, just like spatial variation in saturated conductivity. 

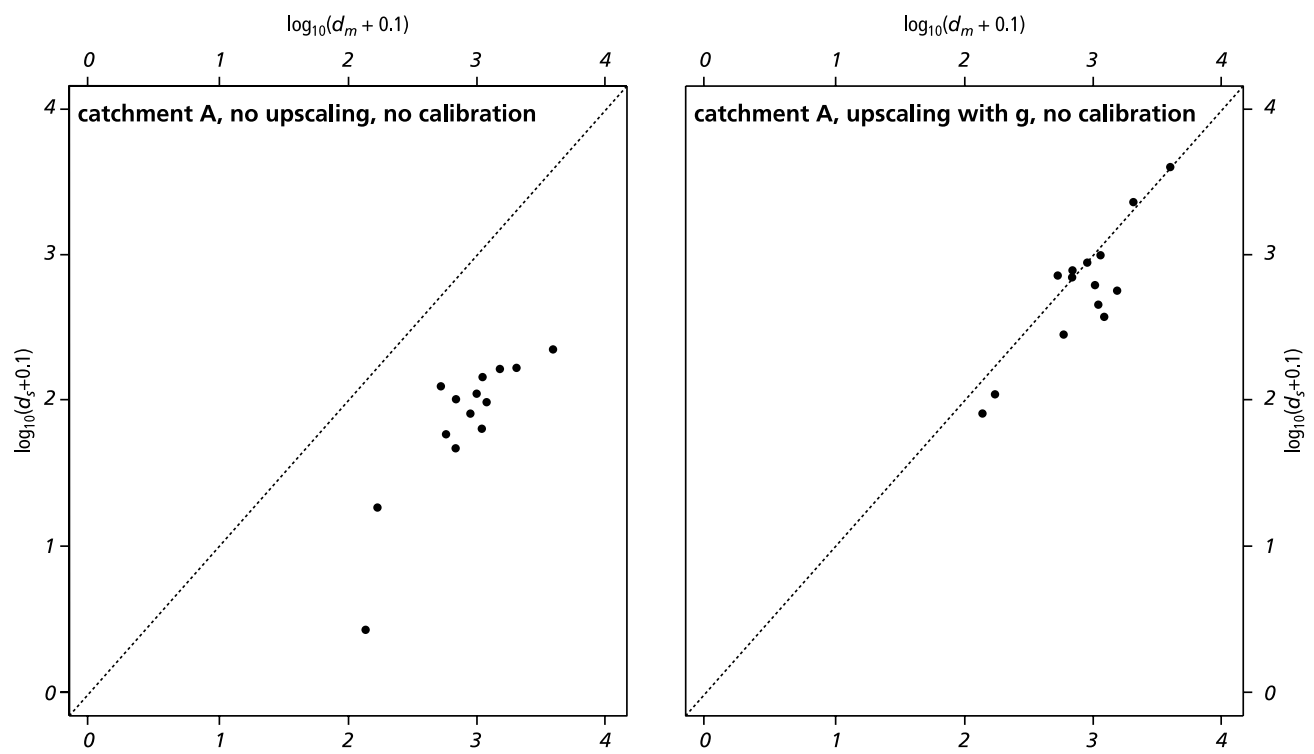

Fig. 18. Catchment A, no calibration of $m_{K_{p}(\mathbf{s})}$. Simulated $\left(d_{\mathrm{s}}, \mathrm{m}^{3}\right)$ against measured $\left(d_{\mathrm{m}}, \mathrm{m}^{3}\right)$ cumulative discharge. Measurement error in cumulative discharge, defined by $d_{\mathrm{m}, \min }$ and $d_{\mathrm{m}, \max }$, is smaller than the size of the dots.
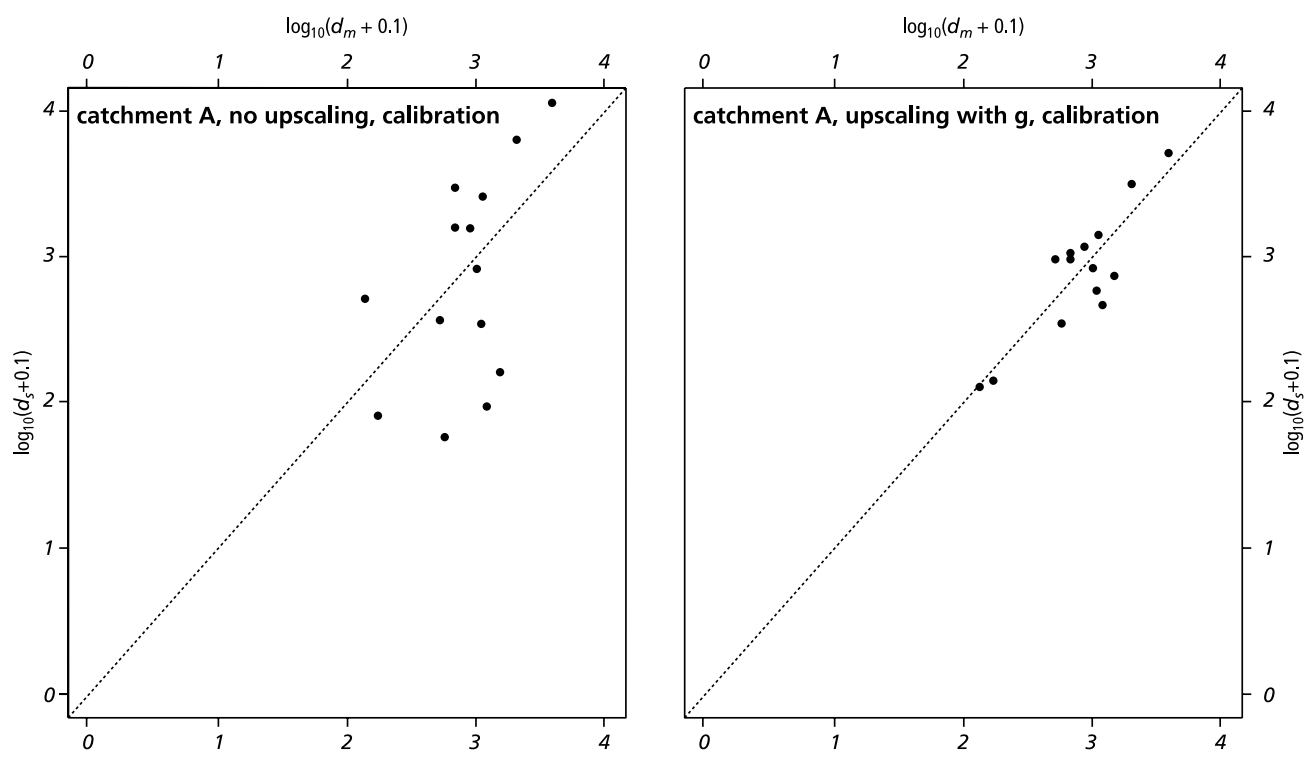

Fig. 19. Catchment A, calibration of $m_{K_{p}(\mathbf{s})}$. Simulated $\left(d_{\mathrm{s}}, \mathrm{m}^{3}\right)$ against measured $\left(d_{\mathrm{m}}, \mathrm{m}^{3}\right)$ cumulative discharge. Measurement error in cumulative discharge, defined by $d_{\mathrm{m}, \min }$ and $d_{\mathrm{m}, \max }$, is smaller than the size of the dots.

Another weakness is related to the calculation used to distribute the inflow $\left(q_{\mathrm{st}}\right)$ to a block over the units at the edge of the block, resulting in an amount of runon $\left(r_{\mathrm{st}}\right)$ for each unit at the edge of the unit, see Eq. (11). For technical reasons, the assumption is made in Eq. (11) of an amount of runon $\left(r_{\mathrm{st}}\right)$ proportional to the catchment area $\left(B_{i}\right)$ of the unit. This results in an overestimation of runon for units with a large catchment area $\left(B_{i}\right)$ because the interaction of rainfall and runoff in the catchment area is not taken into account in (11). Another weakness is the assumption that $G$ can be represented by a purely deterministic upscaling tech- nique $g$. At given values of $q_{\mathrm{st}}$ and $p_{\text {st }}$, Fig. 7 shows that each Monte Carlo sample results in a different value of $i_{\mathrm{b}, \mathrm{st}}$. This spread is not represented by the upscaling technique $g$, which models one value for each combination of $p_{\mathrm{st}}$ and $q_{\mathrm{st}}$. This weakness could be overcome by using stochastic variables for $a, b_{p}$, and $b_{q}$ in the upscaling technique, with parameter distributions fitted to the results of the Monte Carlo simulation. This approach would need a stochastic rainfall-runoff model, too. This weakness related to the upscaling technique $g$ becomes less significant when smaller values of $\sigma_{Z(\mathbf{s})}^{2}$ and $a_{\mathrm{var}}\left(a_{\mathrm{var}}\right.$, with respect to the size of the unit) are measured, since 
the spread in the values of $i_{\mathrm{b} \text {,st }}$ becomes smaller for these cases (results not shown).

Another weakness of the approach is that it ignores the suction force of the soil, which results in values of the infiltration capacity that are greater than the saturated conductivity, in particular at the start of a rainstorm. For the case study described here, the suction force is assumed to have a negligible effect on infiltration, since the process of infiltration is mainly macropore flow, as shown by the high average value of saturated conductivity derived from ring infiltrometer experiments. For other catchments, this is very often not the case.

\section{Conclusions}

Two upscaling techniques have been developed that upscale saturated conductivity at a small support $\left(0.04 \mathrm{~m}^{2}\right)$ to the representative actual infiltration of a block $\left(10^{1}-10^{4} \mathrm{~m}^{2}\right)$ as a function of steady state rainfall and lateral runoff to the block. The stochastic upscaling technique $G$ predicts an increase in representative actual infiltration of the $10^{1}-10^{4} \mathrm{~m}^{2}$ block with (1) increasing rain intensity or lateral runon, (2) increasing mean and decreasing variance, and skewness of saturated conductivity distribution, (3) decreasing spatial scale of variation in saturated conductivity, (4) increasing size of the block, and (5) decreasing bifurcation of the pattern of surface runoff in the block. The direction of these relations corresponds with these found in other modelling and field studies. With upscaling technique $G$, estimates of saturated conductivity at a small support derived from ring infiltrometer measurements can be upscaled to representative actual infiltration at the support of a plot $\left(1 \mathrm{~m}^{2}\right)$ corresponding to those derived from rainfall simulation experiments at that scale.

The upscaling technique $g$ is a deterministic function with properties derived from $G$, using three parameters to represent the spatial probability distribution of the saturated conductivity and the runoff pattern within the block. These three parameters correlate with parameters describing the spatial probability distribution of the saturated conductivity, derivatives of the digital elevation model at the scale of the block (e.g., slope, curvature), and the characteristic type of surface runoff pattern in the block. Using this correlation, it is possible to parameterize $g$ for each block of a dynamic spatial rainfall-runoff model.

The application of the upscaling techniques $G$ and $g$ to calculate actual infiltration of each block and time step in a dynamic spatial rainfall-runoff model results in differences between simulated and measured cumulative runoff which are much smaller than those found with simulations that use the mean saturated conductivity as infiltration capacity. This is the case for model runs without and with calibration of the mean saturated conductivity, and both for runs on a single hillslope and a small catchment.

\section{Acknowledgments}

Lorna Booth (Department of Mathematics, Utrecht University, the Netherlands) is acknowledged for a number of significant inputs to this research. Many thanks to Simone van Dijck (currently at Alterra, Wageningen, The Netherlands) for providing the data set, and comments to an earlier version of the manuscript. Peter Burrough, Marc Bierkens (Department of Physical Geography, Utrecht University), Willem van Deursen (Carthago Consultancy, The Netherlands), Karin Pfeffer (University of Amsterdam) and three anonymous reviewers are thanked for their comments to earlier versions of the manuscript.

\section{Appendix A}

This appendix is co-authored by Lorna Booth, Department of Mathematics, Utrecht University.

We consider here a particular unit $i$. Let $\Delta$ be the standardised total runon to this unit:

$\Delta=p_{\mathrm{st}}+O_{\mathrm{in}, \mathrm{st}}\left(\mathbf{s}_{i}\right)+r_{\mathrm{st}}\left(\mathbf{s}_{i}\right)$.

Let $I_{\mathrm{st}}(\Delta)$ be the standardised infiltration for this particular unit, as a function of $\Delta$. Let $\delta$ be a variable.

Proofs for the properties of the stochastic model

\section{Lemma 1}

$\lim _{\delta \rightarrow 0} E\left(\frac{I_{\mathrm{st}}(\Delta)}{\Delta} \mid \Delta \leqslant \delta\right)=1$.

Proof. Note that $I_{\mathrm{st}}(\Delta) \leqslant \Delta$. Therefore

$E\left(\frac{I_{\mathrm{st}}(\Delta)}{\Delta} \mid \Delta \leqslant \delta\right) \leqslant 1$

Then observe

$$
\begin{aligned}
E\left(\frac{I_{\mathrm{st}}(\Delta)}{\Delta} \mid \Delta \leqslant \delta\right) \geqslant & E\left(\frac{I_{\mathrm{st}}(\Delta)}{\Delta} \mid \Delta \leqslant \delta \cap \Delta \leqslant K_{\mathrm{st}}\left(\mathbf{s}_{i}\right)\right) \\
& \times P\left(\Delta \leqslant K_{\mathrm{st}}\left(\mathbf{s}_{i}\right) \mid \Delta \leqslant \delta\right) .
\end{aligned}
$$

If $\Delta \leqslant K_{\mathrm{st}}\left(\mathbf{s}_{i}\right)$ then $I_{\mathrm{st}}(\Delta) \leqslant \Delta$, so

$$
\begin{aligned}
E\left(\frac{I_{\mathrm{st}}(\Delta)}{\Delta} \mid \Delta \leqslant \delta\right) & \geqslant 1 \cdot P\left(\Delta \leqslant K_{\mathrm{st}}\left(\mathbf{s}_{i}\right) \mid \Delta \leqslant \delta\right) \\
& \geqslant P\left(K_{\mathrm{st}}\left(\mathbf{s}_{i}\right) \geqslant \delta\right)
\end{aligned}
$$

$\lim _{\delta \rightarrow 0} P\left(K_{\mathrm{st}}\left(\mathbf{s}_{i}\right) \geqslant \delta\right)=1$, and combined with (A.1), Lemma 1 follows. 


\section{Lemma 2}

$\lim _{\delta \rightarrow+\infty} E\left(I_{\mathrm{st}}(\Delta) \mid \Delta \geqslant \delta\right)=E\left(K_{\mathrm{st}}\left(\mathbf{s}_{i}\right)\right)$,

$$
\begin{aligned}
& E\left(I_{\mathrm{st}}(\Delta) \mid \Delta \geqslant \delta\right) \\
& \quad \geqslant E\left(I_{\mathrm{st}}(\Delta) \mid \Delta \geqslant \delta \cap K_{\mathrm{st}}\left(\mathbf{s}_{i}\right)<\delta\right) P\left(K_{\mathrm{st}}\left(\mathbf{s}_{i}\right)<\delta\right) \\
& =E\left(K_{\mathrm{st}}\left(\mathbf{s}_{i}\right) \mid \Delta \geqslant \delta \cap K_{\mathrm{st}}\left(\mathbf{s}_{i}\right)<\delta\right) P\left(K_{\mathrm{st}}\left(\mathbf{s}_{i}\right)<\delta\right) \\
& \quad=E\left(K_{\mathrm{st}}\left(\mathbf{s}_{i}\right) \mid K_{\mathrm{st}}\left(\mathbf{s}_{i}\right)<\delta\right) P\left(K_{\mathrm{st}}\left(\mathbf{s}_{i}\right)<\delta\right) .
\end{aligned}
$$

Observe that

$\lim _{\delta \rightarrow \infty} E\left(K_{\mathrm{st}}\left(\mathbf{s}_{i}\right) \mid K_{\mathrm{st}}\left(\mathbf{s}_{i}\right)<\delta\right)=E\left(K_{\mathrm{st}}\left(\mathbf{s}_{i}\right)\right)$

and that

$\lim _{\delta \rightarrow \infty} P\left(K_{\mathrm{st}}\left(\mathbf{s}_{i}\right)<\delta\right)=1$.

Combining (A.2)-(A.4) we see

$\lim _{\delta \rightarrow+\infty} E\left(I_{\mathrm{st}}(\Delta) \mid \Delta \geqslant \delta\right) \geqslant E\left(K_{\mathrm{st}}\left(\mathbf{s}_{i}\right)\right)$.

By the fact that $I_{\mathrm{st}}(\Delta) \leqslant K_{\mathrm{st}}\left(\mathbf{s}_{i}\right)$ and thus

$E\left(I_{\mathrm{st}}(\Delta) \mid \Delta \geqslant \delta\right) \leqslant E\left(K_{\mathrm{st}}\left(\mathbf{s}_{i}\right) \mid \Delta \geqslant \delta\right)=E\left(K_{\mathrm{st}}\left(\mathbf{s}_{i}\right)\right)$.

Lemma 2 follows by combining (A.5) and (A.6).

\section{Appendix B}

This appendix is co-authored by Lorna Booth, Department of Mathematics, Utrecht University.

\section{Explanation of the form of the transfer function}

Notice that

$$
g\left(p_{\mathrm{st}}, 0\right)=h\left[p_{\mathrm{st}}, 1, b_{p}\right] \text { and } g\left(0, q_{\mathrm{st}}\right)=h\left[q_{\mathrm{st}}, a, b_{q}\right] \text {. }
$$

\section{Lemma 1}

$\left.\frac{\partial g\left[p_{\mathrm{st}}, q_{\mathrm{st}}\right]}{\partial p_{\mathrm{st}}}\right|_{\left(p_{\mathrm{st}}, q_{\mathrm{st}}\right)=(0,0)}=1,\left.\quad \frac{\partial g\left[p_{\mathrm{st}}, q_{\mathrm{st}}\right]}{\partial q_{\mathrm{st}}}\right|_{\left(p_{\mathrm{st}}, q_{\mathrm{st}}\right)=(0,0)}=1$.

Notice that $\left.\frac{\partial h[x, d, b]}{\partial x}\right|_{x=0}=1$, combined with (B.1), this gives:

$\left.\frac{\partial g\left[p_{\mathrm{st}}, 0\right]}{\partial p_{\mathrm{st}}}\right|_{p_{\mathrm{st}}=0}=1 \quad$ and $\left.\quad \frac{\partial g\left[0, q_{\mathrm{st}}\right]}{\partial q_{\mathrm{st}}}\right|_{q_{\mathrm{st}}=0}=1$.

\section{Lemma 2}

$\lim _{p_{\mathrm{st}} \rightarrow+\infty} g\left[p_{\mathrm{st}}, q_{\mathrm{st}}\right]=1, \quad \lim _{q_{\mathrm{st}} \rightarrow+\infty} g\left[0, q_{\mathrm{st}}\right]=a$.

Notice that $\lim _{x \rightarrow+\infty} h[x, d, b]=d$ combined with (B.1), this gives

$\lim _{p_{\mathrm{st}} \rightarrow+\infty} g\left[p_{\mathrm{st}}, q_{\mathrm{st}}\right]=1, \quad \lim _{q_{\mathrm{st}} \rightarrow+\infty} g\left[0, q_{\mathrm{st}}\right]=a$.

\section{References}

[1] Aitchison J, Brown JAC. The lognormal distribution, with special reference to its uses in economics. Cambridge: Cambridge University Press; 1957.

[2] Battany MC, Grismer ME. Development of a portable field rainfall simulator for use in hillside vineyard runoff and erosion studies. Hydrol Process 2000;14:1119-29.

[3] Beven K. Changing ideas in hydrology - the case of physicallybased models. J Hydrol 1989;105:157-72.

[4] Beven K. Infiltration excess at the Horton hydrology Laboratory (or not?). J Hydrol 2004;293:219-34.

[5] Bierkens MFP, Finke PA, de Willigen P. Upscaling and downscaling methods for environmental research. Dordrecht: Kluwer; 2000.

[6] Binley A, Beven K, Elgy J. A physically based model of heterogeneous hillslopes. 2. Effective hydraulic conductivities. Water Resour Res 1989;25:1227-33.

[7] Blöschl G. Scale and scaling in hydrology. Wien: Technische Universität Wien, Institut für Hydraulik, Gewässerkunde und Wässerwirtschaft; 1996.

[8] Blöschl G, Grayson RB, Sivapalan M. On the representative elementary area (REA) concept and its utility for distributed rainfall-runoff modeling. Hydrol Process 1995;9:313-30.

[9] Blöschl G, Sivapalan M. Scale issues in hydrological modeling - a review. Hydrol Process 1995;9:251-90.

[10] Burrough PA, McDonnell RA. Principles of geographical information systems. Oxford: Oxford University Press; 1998.

[11] Burt TP. Infiltration for soil erosion models: some temporal and spatial complications. In: Boardman J, Favis-Mortlock D, editors. Modelling soil erosion by water. 1998.

[12] Buttle JM, House DA. Spatial variability of saturated hydraulic conductivity in shallow macroporous soils in a forested basin. J Hydrol 1997;203:127-42.

[13] Castelli F. A simplified stochastic model for infiltration into a heterogeneous soil forced by random precipitation. Adv Water Resour 1996;19:133-44.

[14] Cerda A. Seasonal variability of infiltration rates under contrasting slope conditions in southeast Spain. Geoderma 1996;69:217-32.

[15] Chaplot V, Le Bissonnais Y. Field measurements of interrill erosion under different slopes and plot sizes. Earth Surf Proc Land 2000;25:145-53.

[16] Chow VT, Maidment DR, Mays LW. Applied hydrology. New York: McGraw-Hill; 1988.

[17] Corradini C, Govindaraju RS, Morbidelli R. Simplified modelling of areal average infiltration at the hillslope scale. Hydrol Process 2002;16:1757-70.

[18] Corradini C, Morbidelli R, Melone F. On the interaction between infiltration and hortonian runoff. J Hydrol 1998;204:52-67.

[19] Croke J, Hairsine P, Fogarty P. Runoff generation and redistribution in logged eucalyptus forests, south-eastern Australia. J Hydrol 1999;216:56-77.

[20] Draper NR, Smith H. Applied regression analysis. New York: Wiley; 1981.

[21] Grant SA, Jabro JD, Fritton DD, Baker DE. A stochastic-model of infiltration which simulates macropore soil-water flow. Water Resour Res 1991;27:1439-46.

[22] Hammersley JM, Handscomb DC. Monte Carlo methods. London: Chapman \& Hall; 1979.

[23] Harms TE, Chanasyk DS. Plot and small-watershed scale runoff from two reclaimed surface-mined watersheds in Alberta. Hydrol Process 2000;14:1327-39.

[24] Hawkins RH, Cundy TW. Steady-state analysis of infiltration and overland flow for spatially-varied hillslopes. Water Resour Bull 1987;23:251-6. 
[25] Hendrayanto, Kosugi K, Mizuyama T. Scaling hydraulic properties of forest soils. Hydrol Process 2000;14:521-38.

[26] Heuvelink GBM. Error propagation in environmental modelling with GIS. London: Taylor \& Francis; 1998.

[27] Horn BKP. Hill shading and the reflectance map. IEEE 1981:14-47.

[28] Joel A, Messing I, Seguel O, Casanova M. Measurement of surface water runoff from plots of two different sizes. Hydrol Process 2002;16:1467-78.

[29] Kamphorst EC, Jetten V, Guerif J, Pitkanen J, Iversen BV, Douglas JT, et al. Predicting depressional storage from soil surface roughness. Soil Sci Soc Am J 2000;64:1749-58.

[30] Lal R. Soil degradative effects of slope length and tillage methods on alfisols in western Nigeria. 1. Runoff, erosion and crop response. Land Degrad Dev 1997;8:201-19.

[31] Lauren JG, Wagenet RJ, Bouma J, Wosten JHM. Variability of saturated hydraulic conductivity in a glossaquic hapludalf with macropores. Soil Sci 1988;145:20-8.

[32] Li R-M, Simons DB, Stevens MA. Nonlinear kinematic wave approximation for water routing. Water Resour Res $1975 ; 11: 245-52$.

[33] Liang X, Xie ZH. A new surface runoff parameterization with subgrid-scale soil heterogeneity for land surface models. Adv Water Resour 2001;24:1173-93.

[34] Loague K, Gander GA. R-5 Revisited. 1. Spatial variability of infiltration on a small rangeland catchment. Water Resour Res 1990;26:957-71.

[35] Mallants D, Mohanty BP, Vervoort A, Feyen J. Spatial analysis of saturated hydraulic conductivity in a soil with macropores. Soil Technol 1997;10:115-31.

[36] Merriam RA. Fog drip from artificial leaves in a fog wind tunnel. Water Resour Res 1973;9:1591-8.

[37] Mertens J, Jacques D, Vanderborght J, Feyen J. Characterisation of the field-saturated hydraulic conductivity on a hillslope: in situ single ring pressure infiltrometer measurements. J Hydrol 2002;263:217-29.

[38] Merz B, Bardossy A, Schiffler GR. Different methods for modelling the areal infiltration of a grass field under heavy precipitation. Hydrol Process 2002;16:1383-402.

[39] Merz B, Plate EJ. An analysis of the effects of spatial variability of soil and soil moisture on runoff. Water Resour Res 1997;33:2909-22.

[40] Nahar N, Govindaraju RS, Corradini C, Morbidelli R. Role of run-on for describing field-scale infiltration and overland flow over spatially variable soils. J Hydrol 2004;286:36-51.

[41] Oreskes N. Evaluation (not validation) of quantitative models. Environ Health Persp 1998;106:1453-60.

[42] PCRaster. 2005. Available from http://pcraster.geo.uu.nl.

[43] Pebesma EJ, Heuvelink GBM. Latin hypercube sampling of gaussian random fields. Technometrics 1999;41:303-12.

[44] Philip JR. The Infiltration joining problem. Water Resour Res 1987;23:2239-45.

[45] Philip JR. Theory of infiltration. Adv Hydrosci 1969;5:215-96.
[46] Ragab R, Cooper JD. Variability of unsaturated zone water transport parameters - implications for hydrological modeling. 2. Predicted vs in-situ measurements and evaluation of methods. J Hydrol 1993;148:133-47.

[47] Russo D. Upscaling of hydraulic conductivity in partially saturated heterogeneous porous formation. Water Resour Res 1992;28:397-409.

[48] Russo D, Bresler E. Soil hydraulic properties as stochastic processes. I. An analysis of field spatial variability. Soil Sci Soc Am J 1981;45:682-7.

[49] Russo D, Russo I, Laufer A. On the spatial variability of parameters of the unsaturated hydraulic conductivity. Water Resour Res 1997;33:947-56.

[50] Sharma ML, Gander GA, Hunt CG. Spatial variability of infiltration in a watershed. J Hydrol 1980;45:101-22.

[51] Skidmore AK. A comparison of techniques for calculating gradient and aspect from a gridded digital elevation model. Int J Geogr Inf Syst 1989;3:323-34.

[52] Smettem KRJ. Characterization of water entry into a soil with a contrasting textural class: spatial variability of infiltration parameters and influence of macroporosity. Soil Sci 1987;144:167-74.

[53] Smith RE, Diekkrüger B. Effective soil water characteristics and ensemble soil water profiles in heterogeneous soils. Water Resour Res 1996;32:1993-2002.

[54] Smith RE, Hebbert RHB. A Monte Carlo analysis of the hydrologic effects of spatial variability of infiltration. Water Resour Res 1979;15:419-29.

[55] Sullivan M, Warwick JJ, Tyler SW. Quantifying and delineating spatial variations of surface infiltration in a small watershed. $\mathbf{J}$ Hydrol 1996;181:149-68.

[56] Szilagyi J, Parlange MB. A geomorphology-based semi-distributed watershed model. Adv Water Resour 1999;23:177-87.

[57] van de Giesen NC, Stomph TJ, de Ridder N. Scale effects of Hortonian overland flow and rainfall-runoff dynamics in a West African catena landscape. Hydrol Process 2000;14:165-75.

[58] Van Dijck SJE. Effects of agricultural land use on surface runoff and erosion in a Mediterranean area. Utrecht: Utrecht University; 2000.

[59] Viney NR, Sivapalan M. A framework for scaling of hydrologic conceptualizations based on a disaggregation-aggregation approach. Hydrol Process 2004;18:1395-408.

[60] Williams J, Bonell M. The influence of scale of measurement on the spatial and temporal variability of the Philipp infiltration parameters - an experimental study in an Australian savannah woodland. J Hydrol 1988;104:33-51.

[61] Woolhiser DA, Smith RE, Giraldez JV. Effects of spatial variability of saturated hydraulic conductivity on Hortonian overland flow. Water Resour Res 1996;32:671-8.

[62] Yu B, Rose CW, Coughlan KJ, Fentie B. Plot-scale rainfallrunoff characteristics and modeling at six sites in Australia and Southeast Asia. T Asae 1997;40:1295-303.

[63] Zevenbergen LW, Thorne CR. Quantitative analysis of land surface topography. Earth Surf Proc Land 1987;12:47-56. 